4

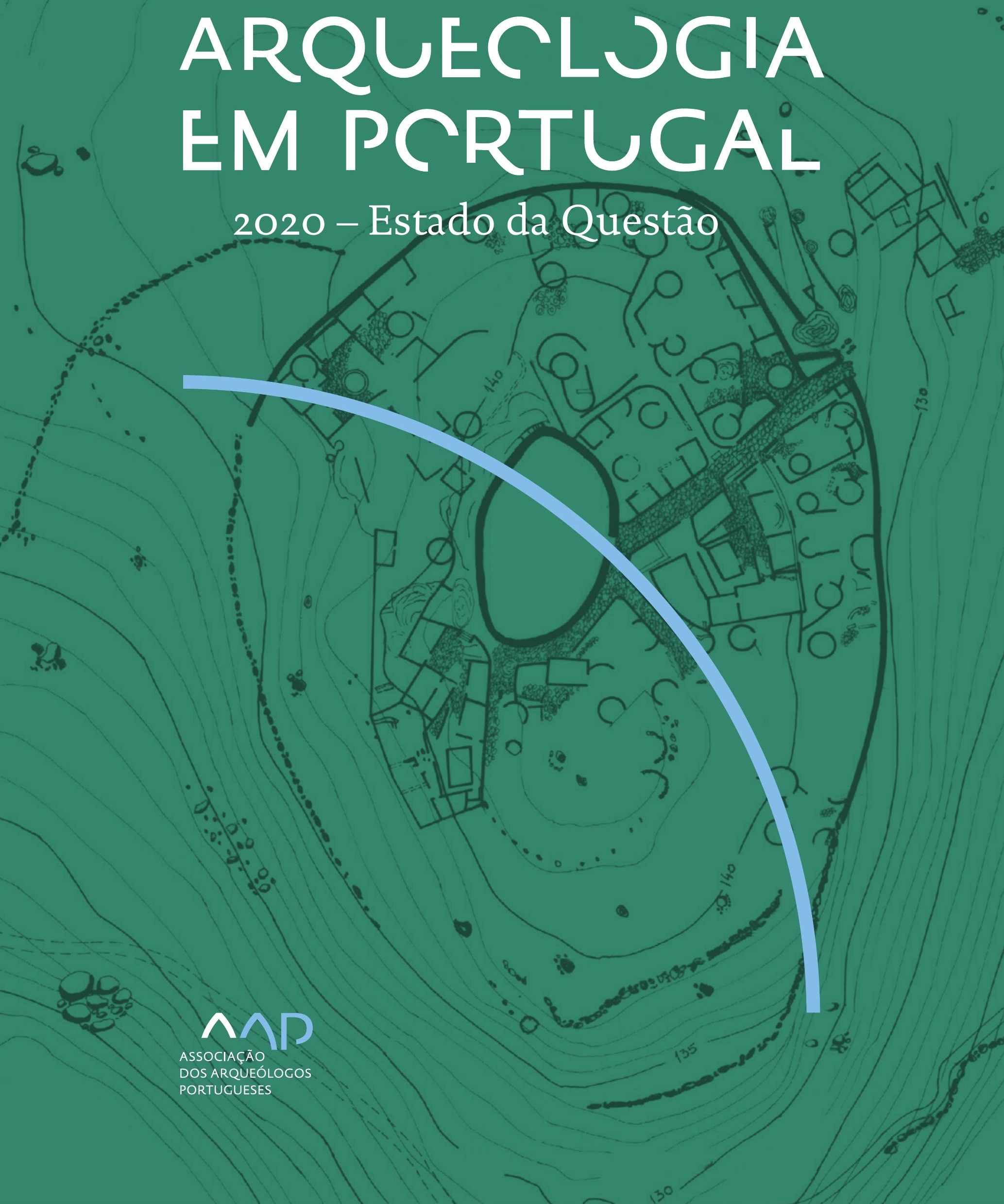


Coordenação editorial: José Morais Arnaud, César Neves e Andrea Martins Design gráfico: Flatland Design

AAP - ISBN: 978-972-9451-89-8

CITCEM - ISBN: 978-989-8970-25-1

Associação dos Arqueólogos Portugueses e CITCEM

Lisboa, 2020

O conteúdo dos artigos é da inteira responsabilidade dos autores. Sendo assim a Associação dos Arqueólogos Portugueses declina qualquer responsabilidade por eventuais equívocos ou questões de ordem ética e legal.

Desenho de capa:

Planta do castro de Monte Mozinho (Museu Municipal de Penafiel).

\section{$\hat{\wedge} \mathrm{P}$}

DOS ARQUEÓLOGOS PORTUGUESES

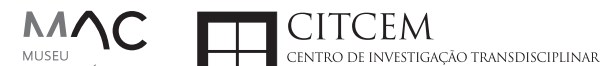
MUSEU
ARQUELLÓGICO
DO CARMO
U.PORTO

FLUP FACULDADE DE LETRAS
UNIVERSIDADE DO PORTO

Apoio

EC para a Ciência 


\section{Índice}

15 Prefácio

José Morais Arnaud

\section{Historiografia e Teoria}

17 Território, comunidade, memória e emoção: a contribuição da história da arqueologia (algumas primeiras e breves reflexões)

Ana Cristina Martins

25 Como descolonizar a arqueologia portuguesa?

Rui Gomes Coelho

41 Arqueologia e Modernidade: uma revisitação pessoal e breve de alguns aspetos da obra homónima de Julian Thomas de 2004

Vítor Oliveira Jorge

57 Dados para a História das Mulheres na Arqueologia portuguesa, dos finais do século XIX aos inícios do século XX: números, nomes e tabelas

Filipa Dimas / Mariana Diniz

73 Retractos da arqueologia portuguesa na imprensa: (in)visibilidades no feminino

Catarina Costeira / Elsa Luís

85 Arqueologia e Arqueólogos no Norte de Portugal Jacinta Bugalhão

101 Vieira Guimarães (1864-1939) e a arqueologia em Tomar: uma abordagem sobre o território e as gentes

João Amendoeira Peixoto / Ana Cristina Martins

115 Os memoráveis? A arqueologia algarvia na imprensa nacional e regional na presente centúria (2001-2019): características, visões do(s) passado(s) e a arqueologia

enquanto marca

Frederico Agosto / João Silva

129 A Evolução da Arqueologia Urbana e a Valorização Patrimonial no Barlavento Algarvio: Os casos de Portimão e Silves

Artur Mateus / Diogo Varandas / Rafael Boavida

\section{Gestão, Valorização e Salvaguarda do Património}

145 O Caderno Reivindicativo e as condições de trabalho em Arqueologia Miguel Rocha / Liliana Matias Carvalho / Regis Barbosa / Mauro Correia / Sara Simões / Jacinta Bugalhão / Sara Brito / Liliana Veríssimo Carvalho / Richard Peace / Pedro Peça / Cézer Santos

155 Os Estudos de Impacte Patrimonial como elemento para uma estratégia sustentável de minimização de impactes no âmbito de reconversões agrícolas Tiago do Pereiro

165 Salvaguarda de Património arqueológico em operações florestais: gestão e sensibilização Filipa Bragança / Gertrudes Zambujo / Sandra Lourenço / Belém Paiva / Carlos Banha / Frederico Tatá Regala / Helena Moura / Jacinta Bugalhão / João Marques / José Correia / Pedro Faria / Samuel Melro

179 Os valores do Património: uma investigação sobre os Sítios Pré-históricos de Arte Rupestre do Vale do Rio Côa e de Siega Verde José Paulo Francisco 
189 Conjugando recursos arqueológicos e naturais para potenciar as visitas ao Geoparque Litoral de Viana do Castelo (Noroeste de Portugal)

Hugo A. Sampaio / Ana M.S. Bettencourt / Susana Marinho / Ricardo Carvalhido

203 Áreas de Potencial Arqueológico na Região do Médio Tejo: Modelo Espacial Preditivo Rita Ferreira Anastácio / Ana Filipa Martins / Luiz Oosterbeek

223 Património Arqueológico e Gestão Territorial: O contributo da Arqueologia para a revisão do PDM de Avis

Ana Cristina Ribeiro

237 A coleção arqueológica do extinto Museu Municipal do Porto - Origens, Percursos e Estudos

Sónia Couto

251 Valpaços - uma nova carta arqueológica

Pedro Pereira / Maria de Fátima Casares Machado

263 Arqueologia na Cidade de Peniche

Adriano Constantino / Luís Rendeiro

273 Arqueologia Urbana: a cidade de Lagos como caso de Estudo Cátia Neto

285 Estratégias de promoção do património cultural subaquático nos Açores. O caso da ilha do Faial

José Luís Neto / José Bettencourt / Luís Borges / Pedro Parreira

297 Carta Arqueológica da Cidade Velha: Uma primeira abordagem

Jaylson Monteiro / Nireide Tavares / Sara da Veiga / Claudino Ramos / Edson Brito /

Carlos Carvalho / Francisco Moreira / Adalberto Tavares

311 Antropologia Virtual: novas metodologias para a análise morfológica e funcional Ricardo Miguel Godinho / Célia Gonçalves

\section{Didáctica da Arqueologia}

327 Como os projetos de Arqueologia podem contribuir para uma comunidade culturalmente mais consciente Alexandra Figueiredo / Claúdio Monteiro / Adolfo Silveira / Ricardo Lopes

337 Educação Patrimonial - Um cidadão esclarecido é um cidadão ativo! Ana Paula Almeida

351 A aproximação da Arqueologia à sala de aula: um caso de estudo no $3^{\circ}$ ciclo do Ensino Básico Luís Serrão Gil

363 Arqueologia 3.o - Pensar e comunicar a Arqueologia para um futuro sustentável Mónica Rolo

377 “Conversa de Arqueólogos" - Divulgar a Arqueologia em tempos de Pandemia Diogo Teixeira Dias

389 Escola Profissional de Arqueologia: desafios e oportunidades Susana Nunes / Dulcineia Pinto / Júlia Silva / Ana Mascarenhas

399 Os Museus de Arqueologia e os Jovens: a oferta educativa para o público adolescente Beatriz Correia Barata / Leonor Medeiros

411 O museu universitário como mediador entre a ciência e a sociedade: o exemplo da secção de arqueologia no Museu de História Natural e da Ciência da Universidade do Porto (MHNC-UP)

Rita Gaspar 
421 Museu de Lanifícios: Real Fábrica de Panos. Atividades no âmbito da Arqueologia Beatriz Correia Barata / Rita Salvado

427 Arqueologia Pública e o caso da localidade da Mata (Torres Novas) Cláudia Manso / Ana Rita Ferreira / Cristiana Ferreira / Vanessa Cardoso Antunes

431 Do sítio arqueológico ao museu: um percurso (também) didático Lídia Fernandes

447 Estão todos convidados para a Festa! E para dançar também... O projecto do Serviço Educativo do Museu Arqueológico do Carmo na $5^{\underline{a}}$ Edição da Festa da Arqueologia Rita Pires dos Santos

459 O “Clã de Carenque”, um projeto didático de arqueologia Eduardo Gonzalez Rocha

469 Mediação cultural: peixe que puxa carroça nas Ruínas Romanas de Troia Inês Vaz Pinto / Ana Patrícia Magalhães / Patrícia Brum / Filipa Santos

481 Didática Arqueológica, experiências do Projeto Mértola Vila Museu Maria de Fátima Palma / Clara Rodrigues / Susana Gómez / Lígia Rafael

\section{Arte Rupestre}

497 Os inventários de arte rupestre em Portugal Mila Simões de Abreu

513 O projeto FIRST-ART - conservação, documentação e gestão das primeiras manifestações de arte rupestre no Sudoeste da Península Ibérica: as grutas do Escoural e Maltravieso Sara Garcês / Hipólito Collado / José Julio García Arranz / Luiz Oosterbeek / António Carlos Silva / Pierluigi Rosina / Hugo Gomes / Anabela Borralheiro Pereira / George Nash / Esmeralda Gomes / Nelson Almeida / Carlos Carpetudo

523 Trabalhos de documentação de arte paleolítica realizados no âmbito do projeto PalæoCôa André Tomás Santos / António Fernando Barbosa / Luís Luís / Marcelo Silvestre / Thierry Aubry

537 Imagens fantasmagóricas, silhuetas elusivas: as figuras humanas na arte do Paleolítico Superior da região do Côa Mário Reis

$55^{1}$ Os motivos zoomórficos representados nas placas de tear de Vila Nova de São Pedro (Azambuja, Portugal) Andrea Martins / César Neves / José M. Arnaud / Mariana Diniz

571 Arte Rupestre do Monte de Góios (Lanhelas, Caminha). Síntese dos resultados dos trabalhos efectuados em 2007-2009 Mário Varela Gomes

599 Gravuras rupestres de barquiformes no Monte de S. Romão, Guimarães, Noroeste de Portugal Daniela Cardoso

613 Círculos segmentados gravados na Bacia do Rio Lima (Noroeste de Portugal): contributos para o seu estudo Diogo Marinho / Ana M.S. Bettencourt / Hugo Aluai Sampaio

631 Equídeos gravados no curso inferior do Rio Mouro, Monção (NW Portugal). Análise preliminar Coutinho, L.M. / Bettencourt, A.M.S / Sampaio, Hugo A.S

645 Paletas na Arte Rupestre do Noroeste de Portugal. Inventário preliminar Bruna Sousa Afonso / Ana M. S. Bettencourt / Hugo A. Sampaio 


\section{Pré-História}

661 O projeto Miño/Minho: balanço de quatro anos de trabalhos arqueológicos Sérgio Monteiro-Rodrigues / João Pedro Cunha-Ribeiro / Eduardo Méndez-Quintas / Carlos Ferreira / Pedro Xavier / José Meireles / Alberto Gomes / Manuel Santonja / Alfredo Pérez-González

677 A ocupação paleolítica da margem esquerda do Baixo Minho: a indústria lítica do sítio de Pedreiras 2 (Monção, Portugal) e a sua integração no contexto regional Carlos Ferreira / João Pedro Cunha-Ribeiro / Sérgio Monteiro-Rodrigues / Eduardo Méndez-Quintas / Pedro Xavier / José Meireles / Alberto Gomes / Manuel Santonja / Alfredo Pérez-González

693 O sítio acheulense do Plistocénico médio da Gruta da Aroeira Joan Daura / Montserrat Sanz / Filipa Rodrigues / Pedro Souto / João Zilhão

703 As sociedades neandertais no Barlavento algarvio: modelos preditivos com recurso aos SIG

Daniela Maio

715 A utilização de quartzo durante o Paleolítico Superior no território dos vales dos rios Vouga e Côa

Cristina Gameiro / Thierry Aubry / Bárbara Costa / Sérgio Gomes / Luís Luís / Carmen Manzano / André Tomás Santos

733 Uma perspetiva diacrónica da ocupação do concheiro do Cabeço da Amoreira (Muge, Portugal) a partir da tecnologia lítica Joana Belmiro / João Cascalheira / Célia Gonçalves

745 Novos dados sobre a Pré-história Antiga no concelho de Palmela. A intervenção arqueológica no sítio do Poceirão I

Michelle Teixeira Santos

757 Problemas em torno de Datas Absolutas Pré-Históricas no Norte do Alentejo Jorge de Oliveira

771 Povoamento pré-histórico nas áreas montanhosas do NO de Portugal: o Abrigo 1 de Vale de Cerdeira Pedro Xavier / José Meireles / Carlos Alves

783 Apreciação do povoamento do Neolítico Inicial na Baixa Bacia do Douro. A Lavra I (Serra da Aboboreira) como caso de estudo Maria de Jesus Sanches

797 O Processo de Neolitização na Plataforma do Mondego: os dados do Sector C do Outeiro dos Castelos de Beijós (Carregal do Sal)

João Carlos de Senna-Martinez / José Manuel Quintã Ventura / Andreia Carvalho / Cíntia Maurício

823 Novos trabalhos na Lapa da Bugalheira (Almonda, Torres Novas) Filipa Rodrigues / Pedro Souto / Artur Ferreira / Alexandre Varanda / Luís Gomes / Helena Gomes / João Zilhão

837 A pedra polida e afeiçoada do sítio do Neolítico médio da Moita do Ourives (Benavente, Portugal)

César Neves

857 Casal do Outeiro (Encarnação, Mafra): novos contributos para o conhecimento do povoamento do Neolítico final na Península de Lisboa.

Cátia Delicado / Carlos Maneira e Costa / Marta Miranda / Ana Catarina Sousa

873 Stresse infantil, morbilidade e mortalidade no sítio arqueológico do Neolítico Final/ Calcolítico ( $4^{\circ}$ e $3^{\circ}$ milénio a.C.) do Monte do Carrascal 2 (Ferreira do Alentejo, Beja) Liliana Matias de Carvalho / Sofia N. Wasterlain 
885 Come together: O Conjunto Megalítico das Motas (Monção, Viana do Castelo) e as expressões Campaniformes do Alto Minho Ana Catarina Basílio / Rui Ramos

899 Trabalhos arqueológicos no sítio Calcolítico da Pedreira do Poio Carla Magalhães / João Muralha / Mário Reis / António Batarda Fernandes

913 O sítio arqueológico de Castanheiro do Vento. Da arquitectura do sítio à arquitectura de um território João Muralha Cardoso

925 Estudo zooarqueológico das faunas do Calcolítico final de Vila Nova de São Pedro (Azambuja, Portugal): Campanhas de 2017 e 2018 Cleia Detry / Ana Catarina Francisco / Mariana Diniz / Andrea Martins / César Neves / José Morais Arnaud

943 As faunas depositadas no Museu Arqueológico do Carmo provenientes de Vila Nova de São Pedro (Azambuja): as campanhas de 1937 a 1967 Ana Catarina Francisco / Cleia Detry / César Neves / Andrea Martins / Mariana Diniz / José Morais Arnaud

959 Análise funcional de material lítico em sílex do castro de Vila Nova de S. Pedro (Azambuja, Portugal): uma primeira abordagem Rafael Lima

971 O recinto da Folha do Ouro 1 (Serpa) no contexto dos recintos de fossos calcolíticos alentejanos

António Carlos Valera / Tiago do Pereiro / Pedro Valério / António M. Monge Soares

\section{Proto-História}

987 Produção de sal marinho na Idade do Bronze do noroeste Português. Alguns dados para uma reflexão

Ana M. S. Bettencourt / Sara Luz / Nuno Oliveira / Pedro P. Simões / Maria Isabel C. Alves / Emílio Abad-Vidal

1001 A estátua-menir do Pedrão ou de São Bartolomeu do Mar (Esposende, noroeste de Portugal) no contexto arqueológico da fachada costeira de entre os rios Neiva e Cávado Ana M. S. Bettencourt / Manuel Santos-Estévez / Pedro Pimenta Simões / Luís Gonçalves

1015 O Castro do Muro (Vandoma/Baltar, Paredes) - notas para uma biografia de ocupação da Idade do Bronze à Idade Média

Maria Antónia D. Silva / Ana M. S. Bettencourt / António Manuel S. P. Silva / Natália Félix

1031 Do Bronze Final à Idade Média - continuidades e hiatos na ocupação de Povoados em Oliveira de Azeméis João Tiago Tavares / Adriaan de Man

1041 As faunas do final da Idade do Bronze no Sul de Portugal: leituras desde o Outeiro do Circo (Beja)

Nelson J. Almeida / Íris Dias / Cleia Detry / Eduardo Porfírio / Miguel Serra

1055 A Espada do Monte das Oliveiras (Serpa) - uma arma do Bronze Pleno do Sudoeste Rui M. G. Monge Soares / Pedro Valério / Mariana Nabais / António M. Monge Soares

1065 São Julião da Branca (Albergaria-a-Velha) - Investigação e valorização de um povoado do Bronze Final

António Manuel S. P. Silva / Paulo A. P. Lemos / Sara Almeida e Silva / Edite Martins de Sá

1083 Do castro de S. João ao Mosteiro de Santa Clara: notícia de uma intervenção arqueológica, em Vila do Conde Rui Pinheiro 
1095 O castro de Ovil (Espinho), um quarto de século de investigação - resultados e questões em aberto

Jorge Fernando Salvador / António Manuel S. P. Silva

1111 O Castro de Salreu (Estarreja), um povoado proto-histórico no litoral do Entre Douro e Vouga

Sara Almeida e Silva / António Manuel S. P. Silva / Paulo A. P. Lemos / Edite Martins de Sá

1127 Castro de Nossa Senhora das Necessidades (Sernancelhe): uma primeira análise artefactual Telma Susana O. Ribeiro

${ }_{1141}$ A cividade de Bagunte. O estado atual da investigação Pedro Brochado de Almeida

1153 Zoomorfos na cerâmica da Idade do Ferro no NW Peninsular: inventário, cronologias e significado Nuno Oliveira / Cristina Seoane

1163 Vasos gregos em Portugal: diferentes maneiras de contar a história do intercâmbio cultural na Idade do Ferro

Daniela Ferreira

1175 Os exotica da necrópole da Idade do Ferro do Olival do Senhor dos Mártires (Alcácer do Sal) no seu contexto regional

Francisco B. Gomes

\section{Antiguidade Clássica e Tardia}

1191 O uso de madeira como combustível no sítio da Quinta de Crestelos (Baixo Sabor): da Idade do Ferro à Romanização Filipe Vaz / João Tereso / Sérgio Simões Pereira / José Sastre / Javier Larrazabal Galarza / Susana Cosme / José António Pereira / Israel Espi

1207 Cultivos de Época Romana no Baixo Sabor: continuidade em tempos de mudança? João Pedro Tereso / Sérgio Simões Pereira / Filipe Santos / Luís Seabra / Filipe Vaz

1221 A casa romana na Hispânia: aplicação dos modelos itálicos nas províncias ibéricas Fernanda Magalhães / Diego Machado / Manuela Martins

1235 As pinturas murais romanas da Rua General Sousa Machado, n. ${ }^{5}$ 1, Chaves José Carvalho

1243 Trás do Castelo (Vale de Mir, Pegarinhos, Alijó) - Uma exploração agrícola romana do Douro

Tony Silvino / Pedro Pereira

1255 A sequência de ocupação no quadrante sudeste de Bracara Augusta: as transformações de uma unidade doméstica Lara Fernandes / Manuela Martins

1263 Os Mosaicos com decoração geométrica e geométrico-vegetalista dos sítios arqueológicos da área do Conuentus Bracaraugustanus. Novas abordagens quanto à conservação, restauro, decoração e datação Maria de Fátima Abraços / Licínia Wrench

1277 “Casa Romana” do Castro de São Domingos (Cristelos, Lousada): Escavação, Estudo e Musealização Paulo André de P. Lemos

1291 A arqueobotânica no Castro de Guifões (Matosinhos, Noroeste de Portugal): O primeiro estudo carpológico

Luís Seabra / Andreia Arezes / Catarina Magalhães / José Varela / João Pedro Tereso 
1305 Um Horreum Augustano na Foz do Douro (Monte do Castelo de Gaia, Vila Nova de Gaia) Rui Ramos

1311 Ponderais romanos na Lusitânia: padrões, formas, materiais e contextos de utilização Diego Barrios Rodríguez

1323 Um almofariz centro-itálico na foz do Mondego

Marco Penajoia

1335 Estruturas romanas de Carnide - Lisboa Luísa Batalha / Mário Monteiro / Guilherme Cardoso

1347 O contexto funerário do sector da "necrópole NO" da Rua das Portas de S. Antão (Lisboa): o espaço, os artefactos, os indivíduos e a sua interconectividade na interpretação do passado Sílvia Loja, José Carlos Quaresma, Nelson Cabaço, Marina Lourenço, Sílvia Casimiro, Rodrigo Banha da Silva, Francisca Alves-Cardoso

${ }_{1361}$ Povoamento em época Romana na Amadora - resultados de um projeto pluridisciplinar Gisela Encarnação / Vanessa Dias

1371 A Arquitectura Residencial em Mirobriga (Santiago do Cacém): contributo a partir de um estudo de caso Filipe Sousa / Catarina Felício

${ }_{1385}$ O fim do ciclo. Saneamento e gestão de resíduos nos edifícios termais de Mirobriga (Santiago do Cacém)

Catarina Felício / Filipe Sousa

1399 Balsa, Topografia e Urbanismo de uma Cidade Portuária Vítor Silva Dias / João Pedro Bernardes / Celso Candeias / Cristina Tété Garcia

1413 No Largo das Mouras Velhas em Faro (2017): novas evidências da necrópole norte de Ossonoba e da sua ocupação medieval Ricardo Costeira da Silva / Paulo Botelho / Fernando Santos / Liliana Nunes

1429 Instrumentos de pesca recuperados numa fábrica de salga em Ossonoba (Faro) Inês Rasteiro / Ricardo Costeira da Silva / Paulo Botelho

1439 A Necrópole Romana do Eirô, Duas Igrejas (Penafiel): intervenção arqueológica de 2016 Laura Sousa / Teresa Soeiro

1457 Ritual, descarte ou afetividade? A presença de Canis lupus familiaris na Necrópole Noroeste de Olisipo (Lisboa)

Beatriz Calapez Santos / Sofia Simões Pereira / Rodrigo Banha da Silva / Sílvia Casimiro / Cleia Detry / Francisca Alves Cardoso

1467 Dinâmicas económicas em Bracara na Antiguidade Tardia Diego Machado / Manuela Martins / Fernanda Magalhães / Natália Botica

1479 Cerâmicas e Vidros da Antiguidade Tardia do Edifício sob a Igreja do Bom Jesus (Vila Nova de Gaia) Joaquim Filipe Ramos

1493 Novos contributos para a topografia histórica de Mértola no período romano e na Antiguidade Tardia Virgílio Lopes

\section{8. Época Medieval}

1511 Cerâmicas islâmicas no Garb setentrional "português": algumas evidências e incógnitas Constança dos Santos / Helena Catarino / Susana Gómez / Maria José Gonçalves / Isabel Inácio / Gonçalo Lopes / Jacinta Bugalhão / Sandra Cavaco / Jaquelina Covaneiro / Isabel Cristina Fernandes / Ana Sofia Gomes 
1525 Contributo para o conhecimento da cosmética islâmica, em Silves, durante a Idade Média Rosa Varela Gomes

1537 Yábura e o seu território - uma análise histórico-arqueológica de Évora entre os séculos VIII-XII José Rui Santos

1547 A encosta sul do Castelo de Palmela - resultados preliminares da escavação arqueológica Luís Filipe Pereira / Michelle Teixeira Santos

1559 A igreja de São Lourenço (Mouraria, Lisboa): um conjunto de silos e de cerâmica medieval islâmica

Andreia Filipa Moreira Rodrigues

1571 O registo material de movimentações populacionais no Médio Tejo, durante os séculos XII-XIII. Dois casos de "sunken featured buildings", nos concelhos de Cartaxo e Torres Novas Marco Liberato / Helena Santos / Nuno Santos

1585 O nordeste transmontano nos alvores da Idade média. Notas para reflexão Ana Maria da Costa Oliveira

1601 Sepulturas escavadas na rocha do Norte de Portugal e do Vale do Douro: primeiros resultados do Projecto SER-NPVD

Mário Jorge Barroca / César Guedes / Andreia Arezes / Ana Maria Oliveira

1619 "Portucalem Castrum Novum" entre o Mediterrâneo e o Atlântico: o estudo dos materiais cerâmicos alto-medievais do arqueossítio da rua de D. Hugo, nํ. 5 (Porto) João Luís Veloso

1627 A Alta Idade Média na fronteira de Lafões: notas preliminares sobre a Arqueologia no Concelho de Vouzela

Manuel Luís Real / Catarina Tente

1641 Um conjunto cerâmico medieval fora de portas: um breve testemunho aveirense Susana Temudo

${ }_{1651}$ Os Lóios do Porto: uma perspetiva integrada no panorama funerário da Baixa Idade Média à Época Moderna em meios urbanos em Portugal

Ana Lema Seabra

1659 O Caminho Português Interior de Santiago como eixo viário na Idade Média Pedro Azevedo

1665 Morfologia Urbana: Um exercício em torno do Castelo de Ourém André Donas-Botto / Jaqueline Pereira

1677 Intervenção arqueológica na Rua Marquês de Pombal/Largo do Espírito Santo (Bucelas, Loures)

Florbela Estêvão / Nathalie Antunes-Ferreira / Dário Ramos Neves / Inês Lisboa

1691 O Cemitério Medieval do Poço do Borratém e a espacialidade funerária na cidade de Lisboa Inês Belém / Vanessa Filipe / Vasco Noronha Vieira / Sónia Ferro / Rodrigo Banha da Silva

1705 Um Espaço Funerário Conventual do séc. XV em Lisboa: o caso do Convento de São Domingos da Cidade Sérgio Pedroso / Sílvia Casimiro / Rodrigo Banha da Silva / Francisca Alves Cardoso

\section{9. Época Moderna e Contemporânea}

1721 Arqueologia Moderna em Portugal: algumas reflexões críticas em torno da quantificação de conjuntos cerâmicos e suas inferências históricas e antropológicas Rodrigo Banha da Silva / André Bargão / Sara da Cruz Ferreira

1733 Faianças de dois contextos entre os finais do século XVI e XVIII do Palácio dos Condes de Penafiel, Lisboa

Martim Lopes / Tomás Mesquita 
1747 Um perfil de consumo do século XVIII na foz do Tejo: O caso do Mercado da Ribeira, Lisboa Sara da Cruz Ferreira / Rodrigo Banha da Silva / André Bargão

1761 Os Cachimbos dos Séculos XVII e XVIII do Palácio Mesquitela e Convento dos Inglesinhos (Lisboa)

Inês Simão / Marina Pinto / João Pimenta / Sara da Cruz Ferreira / André Bargão / Rodrigo Banha da Silva

1775 "Tomar os fumos da erua que chamão em Portugal erua sancta». Estudo de Cachimbos provenientes da Rua do Terreiro do Trigo, Lisboa

Miguel Martins de Sousa / José Pedro Henriques / Vanessa Galiza Filipe

1787 Cachimbos de Barro Caulínitico da Sé da Cidade Velha (República de Cabo Verde)

Rodrigo Banha da Silva / João Pimenta / Clementino Amaro

1801 Algumas considerações sobre espólio não cerâmico recuperado no Largo de Jesus (Lisboa) Carlos Boavida

1815 Adereços de vidro, dos séculos XVI-XVIII, procedentes do antigo Convento de Santana de Lisboa (anéis, braceletes e contas)

Joana Gonçalves / Rosa Varela Gomes / Mário Varela Gomes

1837 Da ostentação, luxo e poder à simplicidade do uso quotidiano: arqueologia e simbologia de joias e adornos da Idade Moderna Portuguesa Jéssica Iglésias

1849 Os amuletos em Portugal - dos objetos às superstições: o coral vermelho Alexandra Vieira

1865 Cerâmicas de Vila Franca de Xira nos séculos XV e XVI Eva Pires

1879 «Não passa por teu o que me pertence». Marcas de individualização associadas a faianças do Convento de Nossa Senhora de Aracoeli, Alcácer do Sal Catarina Parreira / Íris Fragoso / Miguel Martins de Sousa

1891 Cerâmica de Leiria: alguns focos de produção

Jaqueline Pereira / André Donas-Botto

1901 Os Fornos na Rua da Biquinha, em Óbidos Hugo Silva / Filipe Oliveira

1909 A casa de Pêro Fernandes, contador dos contos de D. Manuel I: o sítio arqueológico da Silha do Alferes, Seixal (século XVI) Mariana Nunes Ferreira

1921 O Alto da Vigia (Sintra) e a vigilância e defesa da costa Alexandre Gonçalves / Sandra Santos

1937 O contexto da torre sineira da Igreja de Santa Maria de Loures Paulo Calaveira / Martim Lopes

1949 A Necrópole do Hospital Militar do Castelo de São Jorge e as práticas funerárias na Lisboa de Época Moderna Susana Henriques / Liliana Matias de Carvalho / Ana Amarante / Sofia N. Wasterlain

1963 SAND - Sarilhos Grandes Entre dois Mundos: o adro da Igreja e a Paleobiologia dos ossos humanos recuperados

Paula Alves Pereira / Roger Lee Jesus / Bruno M. Magalhães

1975 Expansão urbana da vila de Cascais no século XVII e XVIII: a intervenção arqueológica na Rua da Vitória no 15 a 17

Tiago Pereira / Vanessa Filipe

1987 Novos dados para o conhecimento do Urbanismo de Faro em época Moderna Ana Rosa 
1995 Um exemplo de Arqueologia Urbana em Alcoutim: o Antigo Edifício dos CTT Marco Fernandes / Marta Dias / Alexandra Gradim / Virgílio Lopes / Susana Gómez Martínez

2007 Palácio dos Ferrazes (Rua das Flores/Rua da Vitória, Porto): a cocheira de Domingos Oliveira Maia

Francisco Raimundo

2021 As muitas vidas de um edifício urbano: História, Arqueologia e Antropologia no antigo Recreatório Paroquial de Penafiel Helena Bernardo / Jorge Sampaio / Marta Borges

2035 O convento de Nossa Senhora da Esperança de Ponta Delgada: o contributo da arqueologia para o conhecimento de um monumento identitário João Gonçalves Araújo / N’Zinga Oliveira

2047 Arqueologia na ilha do Corvo... em busca da capela de Nossa Senhora do Rosário Tânia Manuel Casimiro / José Luís Neto / Luís Borges / Pedro Parreira

2059 Perdidos à vista da Costa. Trabalhos arqueológicos subaquáticos na Barra do Tejo Jorge Freire / José Bettencourt / Augusto Salgado

2071 Arqueologia marítima em Cabo Verde: enquadramento e primeiros resultados do projecto CONCHA

José Bettencourt / Adilson Dias / Carlos Lima / Christelle Chouzenoux / Cristóvão Fonseca / Dúnia Pereira / Gonçalo Lopes / Inês Coelho / Jaylson Monteiro / José Lima / Maria Eugénia Alves / Patrícia Carvalho / Tiago Silva

2085 Trabalhos arqueológicos na Cidade Velha (Ribeira Grande de Santiago, Cabo Verde): reflexões sobre um projecto de investigação e divulgação patrimonial André Teixeira / Jaylson Monteiro / Mariana Mateus / Nireide Tavares / Cristovão Fonseca / Gonçalo C. Lopes / Joana Bento Torres / Dúnia Pereira / André Bargão / Aurélie Mayer / Bruno Zélie / Carlos Lima / Christelle Chouzenoux / Inês Henriques / Inês Pinto Coelho / José Lima / Patrícia Carvalho / Tiago Silva

2103 A antiga fortificação de Quelba / Khor Kalba (E.A.U.). Resultados de quatro campanhas de escavações, problemáticas e perspectivas futuras Rui Carita / Rosa Varela Gomes / Mário Varela Gomes / Kamyar Kamyad

2123 Colónias para homens novos: arqueologia da colonização agrária fascista no noroeste ibérico Xurxo Ayán Vila / José Mạ . Señorán Martín 


\title{
ADEREÇOS DE VIDRO, DOS SÉCULOS XVI-XVIII, PROCEDENTES DO ANTIGO CONVENTO DE SANTANA DE LISBOA (ANÉIS, BRACELETES E CONTAS)
}

\author{
Joana Gonçalves ${ }^{1}$, Rosa Varela Gomes ${ }^{2}$, Mário Varela Gomes ${ }^{3}$
}

\begin{abstract}
RESUMO
A escavação de parte do espaço onde se erguia o Convento de Santana de Lisboa (sécs XVI-XIX), proporcionou não só o conhecimento de algumas das suas estruturas, como milhares de artefactos ou os seus fragmentos, entre os quais se contam adereços de vidro. Nestes incluímos anéis, braceletes e significativa colecção de contas, procedentes de lixeiras ou de sepulturas. As contas apresentam acentuado poliformismo e cromatismo, podendo ser classificadas nos finais do século XVI e principalmente na centúria seguinte. São originárias de Itália, Holanda e, talvez, Inglaterra denunciando, tal como o restante espólio, sociedade abastada, de gosto requintado, capaz de recorrer aos circuitos comerciais internacionais, tendo em vista responder à moda de então, mas também à manutenção dos seus estatutos sociais.
\end{abstract}

Palavras-chave: Lisboa, Convento de Santana, Vidros, Anéis, Braceletes, Contas.

\begin{abstract}
The archaeological excavation of a portion of the area were the Santana Convent once stood (Lisbon, $17^{\text {th }}-19^{\text {th }}$ centuries), brought to light some of its structures, has well as thousands of artefacts or their fragments. Amongst them, numerous glass adornments, which include rings, bracelets and a significant collection of beads, collected in cesspits and graves. The beads present an accentuated polymorphism and chromatism, being attributed to the late $16^{\text {th }}$ century and, mainly, to the following one. Their origins can be traced to Italy, Netherlands and, perhaps, England, which denounces, as happens with the remaining testimonies collected, a wealthy society, with exquisite taste, able to access international trading routes to provide not only for the high demands of fashion but also the maintenance of their social status.
\end{abstract}

Keywords: Lisbon, Santana Convent, Glass, Rings, Bracelets, Beads.

\section{INTRODUÇÃO}

O espaço onde se erguia parte do Convento de Santana, na cidade de Lisboa, foi escavado sob direcção de dois dos presentes autores (R.V.G. e M.V.G.) em 2002/2003 e em 2009/2010, dado que ali se viria a construir edifício da Faculdade de Ciências Médicas da Universidade NOVA de Lisboa.
Aquela casa religiosa foi fundada em 1557, com o patrocínio régio de $\mathrm{D}$. João III e da sua esposa $\mathrm{D}$. Catarina, ocupando o local onde antes existia a Ermida de Santana. Em 1561 o projecto do novo convento foi entregue a Miguel de Arruda, falecido circa 1563, pelo que aquele terá sido seguido por outro arquitecto, talvez o seu sobrinho Dionísio de Arruda, beneficiando de ulteriores campanhas de ampliação

\footnotetext{
1. Instituto de Arqueologia e Paleociências da Universidade Nova de Lisboa / Associação dos Arqueólogos Portugueses; joanafrgoncalves@gmail.com

2. Faculdade de Ciências Sociais e Humanas, Instituto de Arqueologia e Paleociências da Universidade Nova de Lisboa / Associação dos Arqueólogos Portugueses; rv.gomes@fcsh.unl.pt

3. Instituto de Arqueologia e Paleociências da Universidade Nova de Lisboa, Academia Portuguesa de Belas Artes, Academia Portuguesa da História, Associação dos Arqueólogos Portugueses; mv.gomes@fcsh.unl.pt
} 
e de obras diversas, chegando a ser um dos maiores conventos da capital. Apesar da Extinção das Ordens Religiosas ter ocorrido em 1834, a última freira de Santana faleceu já quase no final daquele século (1884), com as instalações conventuais já muito degradadas, tendo sido demolidas em 1897 , não sem que tivesse havido alguma polémica, pois ali se guardavam os ossos de Luís Vaz de Camões. Tal ficou a dever-se sobretudo a se querer edificar o Real Instituto Bacteriológico, inaugurado em 19oo, depois designado Instituto Bacteriológico de Câmara Pestana.

Tivemos já oportunidade de dar a conhecer diversos estudos sobre aspectos decorrentes das estruturas e do imenso espólio exumado, nomeadamente no que concerne aos testemunhos arquitectónicos, da igreja e do claustro (Gomes e Gomes, 2007), e à necrópole, aos azulejos (hispano-árabes, de enxaquetado, de padrão, monocromos ou policromos, esponjados) (Almeida, Gomes e Gomes, 2018), cerâmicas finas e comuns (Gomes et alii, 2013), faianças (Gomes, Gomes e Casimiro, 2016), porcelanas chinesas (Gomes, Gomes e Casimiro, 2015; Gomes e Gomes, 2018), vidros millefiori (Valente et alii, 2019), artefactos em matérias duras de origem animal (marfim, osso, tartaruga, madrepérola, coral) (Gomes, Gomes e Gonçalves, 2017) ou em azeviche (Gomes, Gomes e Gonçalves, 2020), brinquedos e miniaturas de cerâmicas (Gomes, Gomes e Casimiro, 2019), etc.

Foi chegada a hora de estudarmos os adereços de vidro, compreendendo anéis, braceletes e contas. Estas constituem o acervo mais numeroso da classe artefactual referida, apresentando tanto acentuado polimorfismo como cromatismo. A colecção de contas é sobretudo procedente de lixeiras, reutilizando poços ou em fossas, e mais raramente de sepulturas. Ela integra exemplares com formas esféricas, subesféricas ou achatadas, as mais comuns, outras ovóides, cilíndricas, prismáticas, lisas, facetadas e torsas, onde se incluem exemplares elaborados com vidro cristalino, translúcido e opaco, de cores diversas, nomeadamente, os muito vistosos de cor azul-turquesa. Talvez menos espectável, no contexto de casa religiosa, foi o termos encontrado restos de produção de contas vítreas, os fragmentos de canudos, ou canas, e de varetas, de vidro incolor ou colorido, com diversas dimensões, que serviam àquela manufactura, assim como contas coladas, aquando da regularização, a quente, das arestas, depois do corte. No conjunto de contas prismáticas existe raro frag- mento de exemplar do tipo chevron, de produção italiana (vetri del malochio). Contas de muito pequenas dimensões comummente designadas missangas serviram, por certo, aplicadas em peças de vestuário profano. Outras, maiores, terão feito parte de colares, mas também de rosários ou de terços. As longas contas prismáticas de cor turquesa, lisas e torsas, de origem veneziana seiscentista, denunciam verdadeira ostentação. Outras, porém, serão originárias dos Países Baixos ou de França, produção que constitui novidade, desconhecendo-se, por ora, manufactura industrial portuguesa de tais artefactos.

\section{ANÉIS}

As escavações nas ruínas do antigo Convento de Santana proporcionaram alguns fragmentos de anéis de vidro, lisos ou decorados com motivo floral e, um deles, com protuberâncias em ambas laterais do aro, do tipo conhecido como anel de martírio, pelo incómodo e dor que provocava o seu uso.

Exumámos alguns fragmentos de anéis similares durante a escavação da Igreja de Santa Maria do Castelo, de Torres Novas, atribuíveis aos séculos XVI e, sobretudo, XVII.

K. Deagan (2002: 124, fig. 6.7) publicou anel, possuindo motivo floral, de vidro moldado, de San Luís de Talimali, na Florida, datado em 1650-170o. Anéis muito pequenos eram usados por crianças ou dependurados em fios, trazidos ao pescoço ou, no caso de serem lisos, terão pertencido a cadeias (Cabart, 1996: 440, 444, fig. 3). Podem ter sido produzidos em Itália ou em alguma pequena oficina de outro país europeu. (Tabela 1)

\section{BRACELETES}

Nas ruínas do Convento de Santana de Lisboa, exumámos apenas quatro fragmentos correspondentes a braceletes. Três produzidas com vidro incolor transparente, apresentando contorno e secção circulares, sendo ocas. Uma delas provém de zona de jardim, alterada e com os sedimentos remexidos pelas obras de edificação do Instituto Bacteriológico, tratando-se de deposição secundária, enquanto outras duas foram descartadas para lixeira, quando se terão partido. O quarto fragmento, de vidro com cor azul-turquesa, maciço, provém do Poço 1.

Com longa tradição no subcontinente indiano e no Mundo Islâmico, tal como na Europa, onde remon- 
tam à Idade do Ferro (La Tène, sécs III-I A.C.), as braceletes de vidro foram também produzidas na Anatólia (Tyana, Kermeshisar), do século III ao XI, Síria (Qsar el-Hayr), Palestina (Hebron), Sinai (al-Tür), Iémen (Kawd am-Saila, Shabwr, Shihr, Adém) (sécs IV-XVI), Qatar, Egipto (al-Fustat, nos séculos IX-XIV e Quseir al-Qasim), Etiópia e na Índia (Sankalia, séc. XIV, Brahmapuri e Arikamedu, na Costa do Coromandel) (Whitcomb, 1983: 106; Patitucci e Uggeri, 1984: 374, 375; Spaer, 1994: 46, 57; Shindo, 2001: 74; Boulogne e Henderson, 2009; Zanon, 2013). Elas surgem na Península Ibérica desde o Período Califal (séc. X), embora fossem mais difundidas durante o Período Nazarí (sécs XIII e XIV) e depois, entre as comunidades judaicas e cristãs, até ao século XVI, como meio apotropaico e profiláctico, acreditando-se no seu poder para prevenir ou curar doenças, como para proteger contra o mau-olhado e a morte, dada a sua forma circular e a cor, sobretudo quando negras, como o azeviche.

As braceletes de vidro, lisas, possuindo secção circular, oval ou plano-convexa, torcidas em espiral, simples ou com aplicações e cabos, foram usadas no Próximo e Médio Oriente, tal como na Europa, por adolescentes, mulheres jovens e até, por crianças, nos braços e pernas, por vezes em pares ou em conjuntos maiores. As de menores dimensões podiam ser penduradas em colares (Malalana Ureña, 1997: 306, 309-311). Dez braceletes de vidro, nas cores azul de cobalto, azul-turquesa e negra, algumas com enrolamentos de cor branca e medindo o, $055 \mathrm{~m}$ a o,o6o m de diâmetro, distribuíam-se pelos dois antebraços de mulher jovem inumada, no século XIII, em Málaga (Malalana Ureña e Hernández, 2014). Também enterramentos, dos finais do século XV ou dos inícios do século XVI, de Madrid (San Andrés), Córdova (Santa Maria) e de muitos outros sítios da Península Ibérica, eram acompanhados por braceletes de vidro, encontradas geralmente nos pulsos, mas também, no caso das crianças, nos tornozelos (Malalana Ureña e Hernandez, 2014: 253).

Fragmentos de braceletes de vidro foram descobertos em contexto do século XVII, com presença portuguesa, no Forte de Jesus (Mombaça, Quénia) (sécs XVII-XIX), cuja origem foi atribuída a produção da Índia Oriental (Kirkman, 1974: 158, 317). Em outros sítios coloniais, portugueses e espanhóis, também se identificaram braceletes, tal como em Qsar es-Seguir, em Marrocos (sécs XV e XVI) (duas delas, com o,053 $\mathrm{m}$ de diâmetro, encontravam-se nos pulsos de uma adolescente, inumada no cemitério da igreja principal), em La Isabella (1493-98), na República Dominicana, ou em Puerto Real, no Haiti (1503-78) (Deagan, 2002: 134, 135).

Conhecem-se fragmentos de braceletes de vidro exumados nas ruínas da Igreja de Santa Maria do Castelo, de Torres Novas (escav. de M. V. G.), embora descontextualizados, assim como procedentes do Poço-Cisterna islâmico de Silves, desactivado e entulhado em finais do século XVI (escav. de R. V. G.e M. V. G.) (Gomes e Gomes, 2017).

A origem de tais artefactos de vidro, exumados na Península Ibérica e Norte de África, pode ter sido a região de Barcelona (Espanha) ou a de Veneza-Murano (Itália), esta última activa desde o século XIII (Redman, 1986: 204). Todavia, muitos destes adereços foram manufacturados em Hebron, o principal centro produtor de vidro do Próximo Oriente, desde o século XIV ao século XIX (Spaer, 1994: 46, 48). Braceletes de vidro de idade pós-medieval da Palestina e regiões vizinhas oferecem diâmetros que variam desde menos de $0,050 \mathrm{~m}$ a $0,075 \mathrm{~m}$, onde exemplares com secção quase triangular parecem ser mais tardios.

A enorme difusão das braceletes de vidro, pode, por certo, dever-se a distintos factores: constituírem adereços não muito dispendiosos, embora vistosos; produzirem som quando entrechocam, usadas nos pulsos ou tornozelos; também por mostrarem, na maioria dos casos, cor negra, como a do azeviche e, acreditar-se conterem as propriedades profilácticas e talismânicas daquele mineral, ou cor azul, como a cor da abóbada celeste; mas ainda, por serem de forma circular. (Tabela 2)

\section{MISSANGAS (CONTAS DE MUITO PEQUENAS DIMENSÕES, SEED BEADS)}

Vários textos que referem pequenas contas de vidro ou pasta vítrea, possuindo $0,002 \mathrm{~m}$ a 0,004 $\mathrm{m}$ de diâmetro, levadas para as colónias europeias na África, Ásia e América, nomeadamente para as portuguesas, fazem a distinção entre a missanga grossa e a missanga miúda, também chamada olho de rola (Sousa, 1967: 46).

Entre os testemunhos do naufrágio da Ponta do Leme Velho (Ilha do Sal, Cabo Verde), navio português do tráfico colonial datado no século XVII, contam-se pequenos blocos de sedimentos concrecionados que conservam grande quantidade de 
missangas, de muito pequenas dimensões. Aquelas ocorrências correspondem, por certo, a carga, transportada a granel, em recipientes que desconhecemos, talvez de madeira, mas que se terão mantido durante algum tempo, após o naufrágio, dado o seu estado aglomerado e o concrecionamento que apresentam. Também aqui se identificaram dois tamanhos distintos de missangas, as que denominámos pequenas, dado terem forma esférica achatada e cerca de $0,005 \mathrm{~m}$ de diâmetro, e as médias, quando ofereciam forma cilíndrica e cerca de 0,006 $\mathrm{m}$ de diâmetro. As missangas pequenas surgiram em três cores, branca, azul de cobalto e azul-turquesa, enquanto as médias eram todas de cor branca.

Usadas na Europa em rosários e adereços, durante o século XVII, as missangas constituíram bens muito apreciadas pelos autóctones de África, da América e da Ásia. O seu valor como objecto de troca foi sempre elevado entre as populações mencionadas, pelo que se incluíram nos sistemas paleomonetários.

Em 1526 é elaborado documento intitulado o Livro de Armação do Navio Santiago (navio de trato real) que parte de Lisboa em direcção à Ilha de Santiago (Cabo Verde), ali deixando alguns produtos não descriminados. No entanto, o mesmo, após escala na Ribeira Grande, dirige-se aos rios da Guiné com diversas mercadorias a bordo, destinadas a serem trocadas por escravos. De entre aqueles bens destacamos as alaquecas, cristalino, matamungo e olho de peixe, variedades que se podem incluir na contaria. As alaquecas (do árabe al-akika) e cristalino designavam pedraria variada, alguma de origem veneziana, com que se faziam jóias de pouca valia, enquanto a designação olho de peixe pode corresponder a pequenas contas de cor azul.

Foram muito apreciadas em toda a África Austral pequenas contas, designadas Maria II, de cor vermelha e com o interior branco, medindo cerca de $3 \mathrm{~mm}$ de diâmetro. Uma peça de fazenda, valia em Angola, na segunda metade do século XIX, 1200 contas Maria II (Sousa, 1967: 46).

As missangas de várias cores e muito pequenas, as missangas miúdas, ou "olho de rola", eram, no século XIX, transaccionadas em fios com uma dezena de elementos, agrupados em conjuntos de dez.

Nas descrições seiscentistas da Guiné, de Francisco Lemos Coelho, em 1669 e 1684, publicadas por Damião Peres, refere-se "contaria miúda preta e branca" que se trocava, com outros produtos, por "couros, cera e marfim" no porto da barra do rio Gâmbia
(Coelho, 1990: 111). Cera, escravos e marfim eram transaccionados com os Felupes de Casamansa e no reino de Jasé, por "ferro e conta avelorio miúda, de cor preta, branca e cor de telha" (Coelho, 1990: 141, 143). As chamadas "contas avelório" (do castelhano abeloiro), correspondem a missangas.

Em Cacheu (Guiné), Mandigas e Soninqués também negociavam vários produtos, no século XVII, a troco de "ferro e contaria", embora preferissem "prata em patacas para fazerem manilhas", algumas vindas da Índia (Coelho, 1990: 159). Ainda no mesmo século se refere que na zona do porto da Borrancheira o "coral miúdo e conta avelorio" serviam para comprar arroz (Coelho, 1990: 228).

O explorador e comerciante Henrique de Carvalho reconheceu, na sua obra sobre os Lunda, o elevado valor simbólico e venal das missangas, usadas em especial pelo sexo feminino: "As missangas e contaria grossa constituem a maior riqueza das mulheres que transformam o corpo em verdadeiras mostras, em que se vêem contas de todas as côres, formas $e$ grandezas, que o commercio portuguez para lá tem levado. Algumas vi que de certo eram de facturas muito antigas, pois o nosso commercio já ahi as não leva" (Carvalho, 189o: 335, 336). O seu papel no sistema de trocas e vendas ficou bem atestado pelo mesmo autor, ao escrever: "As mulheres que possuem estas riquezas e mesmo os homens recorrem a ellas muitas vezes, quando não teem outro recurso, tirando algumas missangas ou contas de que precisam para comprarem o seu pedaço de carne, peixe ou mesmo malufo ou marra (garapa). || Tiram apenas as que são estrictamente precisas na occasião. Sei que Mucanza (o Muatiânvua interino), querendo comprar no Calânhi um pouco de sal para me mandar, tirára do cabello quatro contas grandes apipadas. II As mulheres teem a sua riqueza contada, e a falta de uma missanga ou conta é para a possuidora motivo de grande tristeza" (Carvalho, 1890: 336).

As contas, cujo uso tem longa tradição em África, produzidas em diversos materiais naturais ou de pasta vítrea, possuem significados múltiplos para as populações daquele continente e etnográficas em geral, motivando a sua aquisição usos muito diversificados, devido à excepcional criatividade de tais sociedades. Elas podem ser utilizadas de modos diversos, como ornamento e/ou com valor simbólico e ritual, evidenciando estatutos sociais e bem-estar económico (Handler, 1997: 115).

Foram diversos, na Europa, os centros de produ- 
ção de contas e missangas que Portugal exportava para África, sendo os principais Veneza-Murano, Nuremberga, Boémia (República Checa) e Holanda (Harlem e Roterdão) (Karklins, 1985; Jargstorf, 1995: 72-74). Recentes escavações arqueológicas no bairro judeu de Waterlooplein, em Amesterdão, cujas relações com Portugal se encontram bem comprovadas (Baart, 1988), trouxeram à luz do dia mais de cinquenta mil exemplares de contas de vidro. Esta indústria terá sido iniciada cerca de 1580 e funcionou até 1750 , fornecendo o comércio holandês, inglês, francês e, muito possivelmente, também o espanhol e o português (Dubin, 1987: 112, 113).

Tanto em África, como em outros Continentes, os indígenas sempre preferiram contaria de cores claras, aspecto não só decorrente de simbolismos diversos, como tendo em vista melhor sobressaírem na pele escura. Todavia, no Bailundo (Angola) houve preferência por missangas pretas e na Lunda, por brancas e grossas, a missanga leite (Sousa, 1967: 46). (Tabela 3)

\section{CONTAS DE VIDRO INCOLOR, TRANSPA- RENTE, COM LINHAS BRANCAS}

A escavação das ruínas do Convento de Santana proporcionou apenas quatro exemplares deste tipo de contas. Um com forma cilíndrica e doze linhas verticais, encontrando-se algo queimado (CS/Q219-1), outro com onze linhas verticais, igualmente algo queimado (CS/Q219-2) e duas, fundidas, de forma esférica achatada, com onze linhas brancas (CS/ Q219-27).

Produção veneziana antiga, alcançou os inícios do século XX, sendo muito apreciada e com alto valor na Costa do Ouro, nomeadamente nos Camarões, onde, por vezes, acompanha contas do tipo chevron (Harter, 1981: 12, 13, fig. 5). (Tabela 4)

\section{CONTAS DE VIDRO OPACO DE COR NEGRA}

Exemplares esféricos e esféricos achatados, de cor negra intensa, opacos mas de superfícies brilhantes, parecem querer imitar o azeviche, cujas propriedades profilácticas e apotropaicas tiveram elevada aceitação entre todas as classes das sociedades europeias, tendo sido produzidas na Boémia e em Amsterdão, entre 1550-1750 (Francis, 1994: 38; Dubin, 1987: 112). (Tabela 5)

\section{CONTAS TUBULARES DE COR AZUL-TURQUESA (NUEVA CÁDIZ)}

Conhecem-se exemplares desta categoria de contas, possuindo seç̧ão cilíndrica ou quadrangular, apresentando as superfícies lisas, torsas ou apenas ligeiramente torsas. Os seus comprimentos variam, embora os maiores atinjam 0,0552 m (CS/P2-1).

Estácio da Veiga (1891, est. XXX), deu a conhecer algumas destas contas, como procedentes de Silves e Estômbar, não sendo muito comuns nos contextos europeus.

Em 1905, C. H. Read publicou colar, que incluía contas tubulares de vidro de cor azul-turquesa, a par de vidro cristalino e de cor âmbar, com possível origem veneziana, encontrado em sepultura de chefe tribal em Mansu, próximo de São Jorge da Mina (Elmina), feitoria que os portugueses edificaram e detiveram até à sua tomada pelos Holandeses, em 1637. Esta encontra-se associada à presença do activo comércio, nomeadamente esclavagista, nos séculos XVI e XVII. No ano seguinte, H. H. Johnston (1906: 22-24 figs 17, 18), volta a relatar o achado mencionado e publica contas tubulares azuis, com secção quadrangular, da Libéria, a que atribui procedência mediterrânica, mas anterior à presença europeia naquela região. Estas contas, chamadas pelos arqueólogos americanos Nueva Cádiz, denominação dada por C. H. Fairbanks (1968), conhecidas na América Central ainda no século XVI, chegaram à América do Norte no século XVII (Deagan, 1987: 162-164; Hume, 1991: 54).

M. da C. Rodrigues (1993) publicou conjunto de 29 contas tubulares, prismáticas, direitas ou ligeiramente torsas, encontradas em Luanda e então conservadas no CPHA. Esta investigadora colocou como hipótese terem sido achadas no cemitério da Samba, sendo semelhantes a outras procedentes da Praia do Bispo (Faria, 1974), concluindo pela sua origem no Mediterrâneo Oriental, ali chegadas através do comércio árabe, em data anterior à presença portuguesa. Na mesma linha de raciocínio, também liga as contas do Algarve, publicadas por Estácio da Veiga, à presença islâmica, teses já à data completamente anacrónicas, tanto quanto à origem como à difusão e contexto de tais adornos. A mesma investigadora haveria de dar a conhecer dezasseis contas tubulares, de cor azul-turquesa, descobertas em escavações ocorridas, em Lisboa, na última década do século XX. Dez destas são procedentes da Praça D. Pedro 
IV (Rossio), nove de secção quadrangular, onde se incluem dois exemplares torsos, e um com secção circular. Seis contas tubulares de secção quadrangular, uma das quais torsa, provêm da zona de São Mamede ao Caldas, admitindo-se serem ulteriores aos finais do século XV e anteriores a 1755, dadas as condições de jazida. Cinco das contas da Praça D. Pedro IV encontraram-se em camada arqueológica pré Terramoto de 1755, contendo moedas de D. João V (1706-1750), e uma de D. José (1750-1777). As restantes procedem de estratos mais antigos, mas conturbados (Rodrigues, 1997: 258, 262; 2003: 213, 217). M. da C. Rodrigues (1997: 271-274; 2003: 230-232) insistiu na existência, em Angola, de tais contas em data anterior à presença portuguesa, como na sua vinda para Portugal, trazidas por escravos, que as usariam como identificação étnica, hipóteses destituídas de quaisquer provas. Duas contas tubulares azuis, torsas, foram encontradas em sepultura de Caotinha, a sul de Benguela (Angola) (Gutierrez, 2001: 50).

Quatro contas tubulares, com secção quadrangular, de cor azul-turquesa, inteiras ou fragmentadas, foram encontradas, em 1999-2000, nas ruínas do Palácio dos Marqueses de Marialva, na Praça Luís de Camões, em Lisboa, podendo genericamente serem datadas entre cerca de 1640 e 1755 , cronologia daquela edificação, embora uma delas se associasse a numisma de três réis de 1703 (D. Pedro II) (Torres, 2007: 216, 217, 219, 220, 225). Mais tarde, M. da C. Rodrigues (2014: 12, 13, 36, 37, 85, figs 8 e 9) mencionou a existência de seis de tais contas procedentes daquele local, retornando as suas teses, nomeadamente da existência na África Ocidental, daquelas, em data anterior à presença portuguesa, pondo em causa a sua produção veneziana e argumentando em relação ao seu uso pela população escrava africana em Lisboa, dos séculos XV e XVI, tudo aspectos que nem a informação literária ou a arqueológica sustentam ou, até pelo contrário, infirmam. Conta tubular de cor azul, com secção quadrangular foi encontrada nas escavações arqueológicas, efectuadas, em 1997, na Praça do Município em Lisboa (Rodrigues, 2014: 15). Constitui variante das contas tubulares lisas, com secção circular, o exemplar de vidro com cor azul escura e listas brancas, do Convento de Santana, podendo proceder de oficina italiana, holandesa ou inglesa, da primeira metade do século XVII, dada a conhecida deslocação dos artífices vidreiros italianos para aqueles dois últimos países (Karklins, 1985: 38; Karlins, Dussubieux e Hancock, 2015: 19).
Estas contas, embora não muito comuns, chegaram ao Continente Americano (Texas, Florida, México, Venezuela, Peru) e Filipinas, através do comércio colonial espanhol (Smith e Good, 1982: 41, 42, figs 5, 6; Feinzig, 2017).

Outra variante, de que dispomos apenas de um exemplar, apresenta vidro de cor azul e listas longitudinais de cor vermelha escura. Trata-se de adereço raro, cuja produção pode ser atribuída às oficinas italianas de Veneza ou Murano, ainda do século XVI. E uma outra, embora comum em alguns contextos, tanto medievais como modernos, mostra forma tubular e reduzido diâmetro.

As contas tubulares, produzidas com vidro "puxado", são conhecidas somente a partir da última década do século XV. (Tabela 6)

\section{CONTA TUBULAR, TORSA, DE COR VERDE ESMERALDA}

Pode integrar as contas chamadas Nueva Cádiz, produzidas em Murano, onde eram denominadas, em 1496, parternostri voltati. Contas similares foram encontradas durante escavações arqueológicas em Antuérpia e datadas de 1575 (Jargstorf, 1995: 47, 109). (Tabela 7)

\section{CONTA CHEVRON}

A escavação do Convento de Santana proporcionou apenas um fragmento deste tipo de contas, permitindo reflectirmos sobre ainda tão controversos artefactos.

Também conhecidas por "grandes contas multicolores", "policrómicas", agri/aggry/aigris, ou de rosetta, constituem as ocorrências da denominada conterie que mais atenção suscitaram, desde o século XIX, aos investigadores nacionais, e não só. Produzidas em pasta vítrea, translúcida e opaca, nas cores branca, negra, azul escura e vermelha, cor de tijolo, em seis camadas alternadas, mas a última das quais azul, oferecem forma cilíndrica ou prismática, possuindo as extremidades facetadas, com o aspecto de tronco de pirâmide de base poligonal, com a policromia formando estrela de doze pontas. As maiores chegam a medir o,o7o m de comprimento. Sabe-se, através de informação literária, que foram produzidas nas vidrarias de Veneza e Murano, a partir de 1482 (paternostri a rosette), se não antes, e depois de 1590, na Holanda. O aspecto estrelado, com 
doze raios, chegou a ser conotado com o número de apóstolos de Cristo (Dubin, 1987: 117; Quiggin, 1992: 36-44; Francis, 1994: 64, 65; Jargstorf, 1995: 15, 47). Talvez a mais antiga menção a este tipo de contas corresponda às que, segundo Duarte Pacheco Pereira (1892: 69), eram transaccionadas na feitoria de São Jorge da Mina, em ca 1507, nos seguintes termos: "humas contas azues a que elles chaman coris". Mais tarde, John Barbot $(1732: 348,349)$ mencionou que holandeses e ingleses vendiam, na Costa Ocidental de África, "blue stones called Agry or Accory, very valuable at the Gold Coast" e "Venice beads". Nas primeiras décadas do século XIX, T. E. Bowdich (1819: 218) enviou para o British Museum colar daquelas contas. Em 1851 J. Y. Akerman (pl. 5, nos 9 , 10) deu a conhecer bonita representação aguarelada de contas antigas, entre as quais duas do tipo chevron, uma delas verde, encontrada perto da London Bridge, em 1847.

Julgamos que a primeira notícia, com carácter científico, dedicada especificamente às contas chevron, deve-se a John Brent (1880) e remonta a comunicação académica de sua autoria, de 1872, oito anos depois publicada na revista Archaeologia. Ali se inventariaram as significativas ocorrências de tais contas em Inglaterra, registando-se os locais e condições de origem, quando conhecidos, e as colecções, públicas e privadas a que pertencem as três dezenas de exemplares mencionados, mas também as conservadas em museus europeus ou as procedentes da América do Norte, do Sul e de África (Egipto e Núbia). Estudaram-se novas contas chevron do Museu de Colchester, a par das encontradas no País Axante (Costa do Ouro, Gana), onde o seu valor era igual, em peso, ao do ouro, ou até superior, e se acreditava crescerem no solo (Price, 1883: 65). O. Tischler $(1886: 5,7)$ também dedicou trabalho às contas chevron (aggry-perlen), encontradas na Europa, mencionando o achado daquelas no Rio Grande do Sul (Brasil) e em sepultura peruana, como em África.

Os primeiros exemplares de contas chevron encontrados em Portugal foram publicados pelo arqueólogo pioneiro Estácio da Veiga (1891: 257, 259, 262264, ests XXX, XXXII). Este deu a conhecer doze exemplares provenientes de Silves e Estômbar, que pertenceram à colecção de Júdice dos Santos, mas então depositadas no Gabinete de Numismática e Antiguidades da Biblioteca Nacional. Três daqueles apresentam os topos de forma tronco-piramidal e nove são cilíndricas. Também publicou, com mag- nífico desenho, montagem em colar, de nove contas com as extremidades tronco-piramidais e sete outras lisas, que o Museu Geológico conservava, graças a oferta de Alfredo Bem-Saúde sem que, contudo, se conheça a sua origem. Estácio da Veiga (1891: $262,263)$ refere ainda as contas dos nichos dos Conventos de Chelas (das Albertas, nicho da Madalena, no Claustro, já desaparecido em 1910) e de Marvila, este concluído em 168o, encontrava-se então grandemente vandalizado. O mesmo autor disse guardar, pelo menos, três de tais contas na sua colecção particular, duas com as extremidades facetadas e uma tubular, assim como possuir notícia da existência de dois exemplares no Museu do Rio de Janeiro, encontradas em Linha Grande (Rio Grande do Sul), publicadas mais tarde por A. Childe (1919: 57) que as compara com achados diversos da América do Norte. Estes seriam depois classificados entre a primeira metade do século XVII a meados da centúria seguinte (Smith e Good, 1982; Hume, 1991: 53). Estudo, da autoria de R. C. Temple (1899: 119-121), sobre o valor e circulação monetária em sociedades etnográficas, refere, em tal contexto, as contas de vidro em África e, nomeadamente, as agri, tidas como produzidas em Veneza e para ali levadas pelos portugueses. No entanto, H. H. Johnston (1906: 22-24, fig. 18) defendeu origem mediterrânica, com cronologia "anterior à Renascença", para contas chevron e tubulares azuis, na Libéria, que deu a conhecer.

A. I. Marques da Costa (1910: 69, nota 1, est. VII, fig. 511) publicou conjunto de sete contas chevron, associadas a outras procedentes da Quinta das Mesas, nos arredores de Setúbal, que pertenciam, com fragmentos de porcelana da China e muitas outras contas, ao revestimento de fonte, junto de capela. Também refere fonte e cascata, na Quinta de Brancanes, situada nas proximidades daquela primeira, em cujas paredes se encontravam contas tubulares e de extremidades facetadas do tipo chevron, colocando a hipótese de terem procedência ultramarina ulterior ao século XV. No mesmo ano, G. Pereira (1910: $287,288)$ mencionou embrechado com contas chevron e outras, da Quinta das Lapas (Torres Vedras). Em 1925, A. W. Cardinall assinou artigo no Journal of the Royal African Society, onde trata a origem do nome aggrey/agri dado às contas chevron, na costa ocidental de África, designando "coral azul", da espécie Allopora subviolacea, das contas dos Camarões, como relata a crença de que entre muitas populações, daquela região, tais contas nasceriam 
da terra (Quiggin, 1992: 38), aspecto comparável ao coral, cuja origem é o fundo do mar, chegando aquelas a terem o mesmo valor do ouro, argumentando claramente a sua produção veneziana, e até, ulteriormente, em Birmingham (Reino Unido), embora aquela primeira chegasse através do comércio árabe terrestre a tais paragens, nos início do século XV e, portanto, antes da presença comercial portuguesa. $\mathrm{Na}$ Alemanha, P. Reinecke (1929), argumentou contra as cronologias recuadas atribuídas às contas agri (chevron), que datou como sendo não anteriores ao século XV.

Algo mais tarde, R. de Serpa Pinto (1932) menciona duas contas existentes no Museu de Antropologia da Faculdade de Ciências do Porto, uma vinda do Sul do país, oferecida pelo P. J. Brenha e a outra provinda de Carregal (Sernancelhe), onde era usada ao pescoço contra os "áres ou quebranto", referindo ainda o achado de outros exemplares, no Ribeiro de Valongo (Barroso) e São Julião de Freixo (Ponte de Lima).

Félix Alves Pereira (1927,-29: 49-51, fig. 41; 1933: 29$31,78,120$; 1934) haveria de dar a conhecer as ocorrências procedentes da encosta do Castro de São Julião de Freixo (Ponte de Lima), uma das quais entregou ao Museu Etnológico em 1909, apresentando relação de tais artefactos existentes naquela instituição, onde inclui exemplar de Ganfei (Valença), dezanove fragmentos do nicho da Madalena (Chelas), um comprado em Setúbal e outro em Roma por J. L. de Vasconcellos. Também menciona a existência do mesmo tipo de contas nos embrechados da Quinta das Lapas (Torres Vedras), dos Conventos de Chelas e de Marvila ou de convento, usado como quartel, na Estrela, em Lisboa, colocando como hipótese serem algumas das que se encontram no Museu do Carmo. $\mathrm{O}$ mesmo autor repete antigas teorias que tentaram explicar a origem daqueles adornos, como as velhas teses egípcia ou normanda (séculos IX e X), embora também proponha Murano, a partir do século XV. Quase na mesma data, Armando de Matos (1934) inventariou os poucos exemplares então conhecidos, o encontrado na Quinta de São Salvador em Ganfei (Valença do Minho), outro comprado em 1909 por J. Leite de Vasconcellos no Cairo, mas tido como procedente da Síria, e oito que conservava o Museu da Sociedade de Geografia de Lisboa, vindos da Índia, onde foram encontrados em sepultura, ou sepulturas, tal como estuda três exemplares que se conservavam no Museu Municipal de Azuaga, em Gaia, procedentes da cidade de Luanda, as maiores até agora identificados.

Ainda naquele ano foi publicada notícia do achado, ocorrido no ano anterior, de conta chevron no interior de casa do Castro de Sabroso, que permitiria recordar a tese oriental e antiga da origem de tais adornos (Silva, 1934).

Mário Cardozo (1943) deu a conhecer duas contas chevron, surgidas durante trabalhos agrícolas em São Caetano (Chaves), ao que parece com outras idênticas, talvez constituindo colar. Também refere o achado de contas do mesmo tipo em Vila da Ponte (Trás-os-Montes), uma delas oferecida a Mendes Corrêa para o Museu de Antropologia.

Curiosamente, em volume da Revista de Guimarães, datado de 1955, surgiram três curtos trabalhos sobre as contas, então chamadas policromas. M. Cardozo (1955) escreveu sobre a distribuição de tais artefactos em território nacional, desde o Minho (Valença, Ponte de Lima, Guimarães) e Trás-os-Montes (Barroso, Chaves), passando pelas Beiras (Sernancelhe) e Estremadura (Lisboa, Sintra, Torres Vedras, Setúbal), atingindo o Algarve (Silves, Estombar). Também refere a existência de exemplares no $\mathrm{Mu}$ seu Britânico (15), no de Cantuária (1), nos museus do Louvre e de Copenhaga (2), referindo ainda a sua presença em túmulos índios do Missouri e em outros pontos da América do Norte (10), como em Madagáscar e na Índia, lançando a ideia da sua difusão universal, uma, mais antiga, a partir da Fenícia e Egipto e outra, durante o século XV e seguintes, com origem em Murano (Veneza).

Th. Monod (1952) comparou as duas contas chevron do Museu de Antropologia da Faculdade de Ciências do Porto, com exemplares encontrados na África Ocidental (Camarões, Daomé, Senegal), nada concluindo sobre a sua origem.

Texto de L. Chaves (1955) refere-se principalmente aos exemplares do Museu Etnológico, hoje Museu Nacional de Arqueologia, fazendo revisão das restantes ocorrências. Assim, menciona a mais de meia centena de exemplares, quase todos fragmentados, provindos dos Conventos de Chelas e Marvila, em Lisboa, as duas dezenas do Convento de Brancanes de Setúbal, dois exemplares da Quinta das Mesas, também em Setúbal, a que acima referimos, e outros dois do Convento de Brancanes que pertenceram a Marques da Costa.

J. M. Cordeiro de Sousa $(1954 ; 1955)$ tratou as anteriormente referidas oito contas chevron do Museu da Sociedade de Geografia, de Lisboa, atribuindo- 
-lhes produção fenícia, referindo os embrechados portugueses com contas no mesmo tipo e discorre sobre a sua difusão, juntando às regiões já mencionadas a Escandinávia, o Norte de África, e o México. $\mathrm{O}$ mesmo conjunto de contas seria mais tarde publicado, como de origem italiana, dos séculos XV ou XVI, embora sem alusão às condições do achado (Cantinho, 2008).

Em 1961 e 1964, T. E. Haevernick publicou artigos onde faz a história da investigação das contas chevron e inventaria os exemplares conhecidos, atribuindo a sua produção a Veneza e Amsterdão, durante o século XVII.

F. de Almeida e J. L. de Matos (1970), revelaram conta chevron encontrada no centro da cidade de Luan$\mathrm{da}$, oferecida àquele primeiro arqueólogo. Ao darem a conhecer mais esta ocorrência, referem achados similares nas praias daquela cidade (Cacuaco e Praia do Bispo), indicando como possíveis centros manufactores de tais artefactos, Veneza (1500-180o) e Amesterdão (até 1680). Este tipo de contas tem surgido na Mauritânia, Senegal, Camarões, Nigéria, Congo e Angola (Delarozière, 1994: 78-81, fig. 79), mas também na América do Norte e do Sul (Venezuela, Peru), onde acompanham com as contas tubulares azuis (Deagan, 1987: 164-167, fig. 7.4; Feinzig, 2017: 21, 51).

Escavações em Lisboa têm proporcionado contas chevron, nomeadamente as efectuadas em 1999200o, onde se erguia o Palácio dos Marqueses de Marialva, na actual Praça Luís de Camões. Dali provêm quatro exemplares, com cronologia situada entre cerca de 1640, data da edificação daquele imóvel, e 1755, quando ele caiu devido ao Terramoto (Torres, 2007: 215, 216, 220-223, 229, 230). Todavia, é também referido que ali se encontraram onze exemplares, desconhecendo-se o seu paradeiro (Torres, 2007: 192). M. da C. Rodrigues (2014: 36, 39, fig. 11) indica a existência de uma conta chevron completa e de dois fragmentos de outras.

A. M. Torres $(2007:$ 193, 202) fez referência a embrechados da Capela de Nossa Senhora da Conceição e jardim de palácio em Alcáçovas, do século XVII, contendo contas chevron e tubulares de cor azul (Nueva Cádiz). A mesma autora regista que conta chevron, na Colecção de Antiguidades, da Biblioteca Nacional de Lisboa provém da Amadora (Torres, 2007: 192).

As contas chevron, de diferentes dimensões, obtiveram larga difusão, alcançando zonas diversas de todos os continentes. (Tabela 8)

\section{CONTA DE COR VERMELHA COM O INTERIOR DE COR NEGRA}

Foram produzidas em Veneza, durante a segunda metade do século XVII (Dubin, 1987: 110). (Tabela 9)

\section{CONTAS DE VIDRO DE COR VERMELHA (BORDEAUX), COM LISTAS BRANCAS}

Este tipo de contas, normalmente de forma esférica achatada, produzidas em vidro opaco e com listas verticais de cor branca, foi produzido em Veneza e Murano, desde finais do século XVI a meados do século XVII, mas também na Holanda e em Hammersmith Embankment (Londres), durante o século XVII (Dubin, 1987: 113; Karklins, Dussubieux e Hancock, 2015: 19, 20). (Tabela 10)

\section{CONTAS DE VIDRO DE COR ÂMBAR}

Trata-se de produção veneziana ou francesa, dos finais do século XVI e dos inícios da centúria seguinte (Dubin, 1987: 113). Ruão foi centro produtor de contas, onde trabalharam artífices venezianos, existindo documentos que comprovam a venda de grandes quantidades daquelas para Portugal, "Expédition en Portugal de 676 milliers de patenôtres jaunes et de 58 milliers de patenôtres façon et manufacture de Rouen, 10 janvier 1607 " e de " 5 lives de patenôtres d'ambre, manufacture de Rouen, 19 mars 1607" (Tougard, 1897: 429). V. Magalhães Godinho (1962: 206) mencionou "contas amarelas e verdes de Nuremberg", no comércio português com África, durante o reinado de D. João II. (Tabela 11)

\section{CONTAS OCAS COM APLICAÇÕES DE VIDRO AMARELO}

Identificaram-se apenas dois raros exemplares, unidos por elo metálico, sugerindo pertencerem a terço. Encontrámos paralelo, para este tipo de produção, entre os testemunhos arqueológicos de pequena oficina vidreira de Ruão (Normandia), do século XVII. Esta produziu pequenos objectos de vidro em quantidades limitadas, com decorações variadas, entre os quais contas ocas com aplicações em forma de flor (Cabart, 1996: 440, fig. 3.47). (Tabela 12) 


\section{CONTAS COM DECORAÇÃO DOURADA}

Dois fragmentos de contas tubulares, de vidro branco, opaco, com secção circular, exibem linhas incisas espiraladas preenchidas por dourado. Trata-se de produção rara, sugerindo que a decoração dourada foi efectuada após a conta se encontrar terminada. Sabemos que algumas oficinas, dos chamados "esmaltadores" introduziam motivos decorativos em peças de vidro existentes e até as transformavam. Testemunhos de oficina de "esmaltadores" de Ruão mostrou trabalho de aplicação de ouro em pequenas peças de vidro (Cabart, 1996: 442). (Tabela 13)

\section{OUTRAS CONTAS}

Incluímos nesta categoria as contas com formas ou decorações para os quais não encontrámos paralelos. Conta de vidro azul de cobalto, oferece forma bi-tronco-piramidal hexagonal (paternostro a $f a$ cette), através de lapidação, podendo ter origem em Veneza. Encontra paralelo em exemplar da Liberia (Johnston, 1906: fig. 18). Rara conta periforme apresenta cor verde água. (Tabela 14)

\section{CANAS E VARAS}

A produção de contas de vidro, e de outros artefactos, recorre ao uso de varetas naquele material, chamadas canas (rods), quando perfuradas longitudinalmente, e varas se maciças. No Convento de Santana, conjunto significativo de fragmentos de canas denuncia a produção de pequenos objectos de vidro, nomeadamente de contas. Todavia, as canas podiam também ser segmentadas, ficando com diferentes comprimentos e usadas como contas, uma vez perfuradas em um ou nos dois topos, ou usando a perfuração central.

Colar que integra contas chevron e canas, perfuradas em um dos topos, provém de San Pedro Quitatoni, em Oaxaca (México), de produção hispânica e possivelmente do século XVIII. Também foram encontradas canas em Saint Augustine na Florida, em contexto do século XVIII, remetendo para a produção local de contas e outros adereços de vidro (Deagan, 2002: 131, fig. 6.21). Em Ruão (França), foi escavada área onde existiu, no século XVII, pequena oficina vidreira de "esmaltadores", certamente das muitas que naquela cidade produziam contas e outros adereços exportados para Portugal (Cabart,
1996). Eram espaços pequenos, com poucos artesãos, cujo trabalho dependia de lamparina metálica, com chama insuflada por fole, aumentando a temperatura de modo a fundir o vidro, conforme ilustra a Encyclopédia de Diderot e d'Alembert (1755: 545). (Tabela 15)

\section{ALGUMAS CONCLUSÕES}

Os adereços vítreos cumpriam, e ainda hoje o mesmo ocorre entre muitas comunidades humanas de todos os continentes, funções ornamentais ou de adorno, de pessoas, usados directamente sobre diferentes partes do corpo, nomeadamente visíveis, como em peças de vestuário, mas também em diferentes artefactos, entre os quais alguns de carácter religioso, como os conjuntos organizados em rosários e terços, da cristandade ou as contas de rezar (prayer beads) de outras religiões. Para além daquela função primária houve, por certo, desde sempre, outra, ligada aos anéis e braceletes e principalmente às contas, a apotropaica, dado a simbologia das formas daquelas últimas, principalmente a esférica ou globular, a sua resistência, como as características e origens das matérias-primas em que foram produzidas (cor, textura, brilho, raridade), funcionamento como amuletos (valor mágico das matérias-primas) e talismãs (formas), tornando-as, isoladas e sobretudo constituindo conjuntos, em "objectos de virtude". Estes foram usados por todas as classes sociais e etárias, alguns tornaram-se em bens herdados, sendo capazes de proteger contra a inveja e o mau-olhado (fastinatio), mas ainda de muitos outros males.

No que concerne às contas, elas tiveram valor monetário, chegando em algumas regiões de África a ser igual ao do ouro. Não obstante, as contas foram ainda usadas em jogos e para contar, em ábacos, e, portanto, com funções lúdicas ou ligadas ao cálculo matemático. A presença de contas em sepulturas nem sempre reflecte a existência de adereços ou de rosários e terços que acompanhavam os falecidos, pois antigas tradições, como a que registou, ainda na primeira metade do século XX, Albano Vieira Braga (1943: 88), no concelho de Marco de Canaveses, onde colocavam no caixão "uma moeda de cinco réis, umas contas e uma agulha enfiada. A moeda é para passar no campo de Jusafaz e meter na bôca do Diabo, que lá está de guarda; as contas são para o morto se ir encomendando a Deus, e a agulha para se remendar no outro mundo". A função protectora 
das contas ultrapassa as suas relações com os humanos, em vida ou depois de mortos, pois em Inglaterra lançavam-se contas aos poços para proteger as suas águas (Brent, 1880: 298).

Os adereços vítreos reflectem não só questões de gosto ou estéticos e aspectos idiossincráticos das sociedades humanas, como ideológicos, mas também nos informam sobre redes comerciais, influências e interacções económicas e culturais, constituindo testemunhos com enorme potencial histórico.

A existência de contas de vidro, ou de pasta vítrea, ascende, no território hoje português, à Idade do Bronze Médio (1500-1200 A.C.), de que são testemunhos raros exemplares procedentes do Mediterrâneo Oriental. Todavia, o seu uso desenvolveu-se durante o surto civilizacional ocorrido durante a I Idade do Ferro (séculos VIII-V A.C.), no Sul de Portugal, quando se importaram grandes quantidades de tais adereços, e depois na II Idade do Ferro, momento em que se terá iniciado a sua produção naquele território e em outras regiões ibéricas, a par da de braceletes, também de vidro (Alarcão e Gomes, 1989; 15-19).

Os adereços vítreos exumados nas ruínas do Convento de Santana, de Lisboa, sugerem, na maior parte dos casos, proceder das oficinas italianas de Veneza-Murano, embora seja difícil, não dispondo de análises físicas e químicas, termos certezas. Produções da Boémia e Morávia, muito activas desde 1548 , como as holandesas, podem ter sido responsáveis por alguns exemplares. Todavia, pudemos atribuir algumas contas às manufacturas inglesa $\mathrm{e}$ francesa, cuja importância só agora foi reconhecida através de documentos escritos.

Tal como o restante espólio exumado neste arqueossítio, os adereços de vidro ilustram sociedade abastada, de gosto requintado, capaz de recorrer aos circuitos comerciais internacionais, tendo em vista responder a gosto pessoal e à moda de então, mas também à manutenção dos estatutos sociais, através da posse e exibição de bens materiais de luxo. Jóias e adornos de vidro, eram usados com permissão em algumas instituições religiosas, num quadro longe da austeridade que a fé religiosa e a devoção deveriam impor, aspecto que não deixou de então ser criticado por alguns moralistas.

\section{BIBLIOGRAFIA}

AKERMAN, John Yonge (1851) - Remarks on a coloured drawing of some ancient beads, executed by Benjamin Nightingale, Esq. from specimens in his possession, Archeologia, vol.34(1), pp.46-50.

ALARCÂO, Adília; GOMES, Mário Varela (1989) - Da Proto-História aos Alvores da Idade Média, O Vidro em Portugal, pp. 15-25. Lisboa: Associação Portuguesa de Arqueologia Industrial.

ALMEIDA, Fernando de; MATOS; José Luís Martins de (1970) - Notícias arqueológicas, Actas das I Jornadas Arqueológicas, vol. II, pp. 413-424. Lisboa: Associação dos Arqueólogos Portugueses.

ALMEIDA, Mariana; GOMES, Rosa Varela; GOMES, Mário Varela (2018) - A first approach to the tile collection from the Convento de Santana (Lisbon, Portugal), International Conference Glazed Ceramics in Cultural Heritage, GlazeArt 2018, Sílvia Pereira, Marluci Menezes e José Delgado Rodrigues (eds): 42-44, 251-267. Lisboa: Laboratório Nacional de Engenharia Civil.

ALMEIDA, Mariana; GOMES, Rosa Varela; GOMES, Mário Varela (2020) - Os azulejos do Convento de Santana de Lisboa: primeira abordagem. Arqueologia \& História, vol. 70, pp. 293-309.

BARBOT, John (1732) - A Description of the Coasts of North and South-Guinéa; And of Ethiopia Inferior, Vulgary Angola: Being a New and Accurate Account of the Western Maritime Countries of Africa. London: A \& J Churchill.

BOWDICH, Thomas Edward (1819) - Mission from Cape Coast Castle to Ashantee. London: John Murray.

BRAGA, Alberto Vieira (1943) - Curiosidades de Guimarães, VIII - Mortórios, Revista de Guimarães, vol. LIII (1, 2), pp. 14-97.

BRENT, John (1880) - On glass beads with chevron pattern, Archaeologia, vol. XLV (2), pp. 297-308, 1 pl.

CABART, Hubert (1996) - Un atelier d'émailleur au $17^{\circ}$ siècle à Rouen (France), Annales du $13^{e}$ Congrès de l'Association International pour l'Histoire du Verre, pp. 437-446. Lochem: Association Internationale pour l'Histoire du Verre.

CANTINHO, Manuela (2008) - As contas chevron da Sociedade de Geografia de Lisboa; rosetas tricolores (séc. XV e XVI), Boletim da Sociedade de Geografia de Lisboa, série $126^{\mathrm{a}}, \mathrm{n}^{\mathrm{os}} 1-12$, pp. 247-251.

CARDINALL, Allan Wolsey (1925) - Aggrey beads of the Gold Coast, Journal of the Royal African Society, vol. 24(96), pp. 287-298.

CARDOZO, Mário (1943) - Antiguidades transmontanas. II - contas polícromas de pasta vítrea, Revista de Guimarães, vol. LIII(1, 2), pp. 112-116. 
CARDOZO, Mário (1955) - Breves notas acerca de um tipo conhecido de antigas contas de vidro polícromas, Revista de Guimarães, vol. LXV, pp. 133-136.

CARVALHO, Henrique Augusto Dias de (189o) - Ethnographia e Historia Tradicional dos Povos da Lunda. Lisboa: Imprensa Nacional.

CHAVES, Luís (1955) - Contas de pasta vítrea polícrómicas do Museu Etnológico, Revista de Guimarães, vol. LXV, pp. 137-141, 1 est.

CHILDE, Alberto (1919) - Guia das Colecções de Archeologia Clássica, Museu Nacional do Rio de Janeiro. Rio de Janeiro: Imprensa Nacional.

COSTA, António Inácio Marques da (1910) - Estações prehistoricas dos arredores de Setúbal, Appendice, O Archeologo Português, vol. XV, pp. 55-83, IX ests.

DEAGAN, Kathleen (1987) - Artifacts of the Spanish Colonies of Florida and the Caribbean, 150o-18oo. vol. I, Ceramics, Glassware and Beads, Washington D.C.: Smithsonian Institution Press.

DEAGAN, Kathleen (2002) - Artifacts of the Spanish Colonies of Florida and the Caribbean, 1500-180o. vol. II, Portable Personal Possessions, Washington D.C.: Smithsonian Institution Press.

DELAROZIÈRE, Marie-Françoise (1994) - Perles d’Afrique. Aix-en-Provence: Édisud.

DIDEROT, Denis; D’ALEMBERT, Jean le Rond (1755) - Encyclopédie ou Dictionnaire Raisonné des Sciences, des Arts et des Métiers, vol. V. Paris: André Le Breton Éditeur.

DUBIN, Lois Sherr (1987) - The History of Beads. From 30, oo B.C. to the Present. New York: Harry N. Abrams, Inc.

FAIRBANKS, Charles H. (1968) - Early Spanish Colonial beads, Conference on Historic Sites Archaeology Papers, vol. (1), pp. 3-21.

FARIA, Bettencourt (1974) - Subsídios para um melhor conhecimento das contas de vidro encontradas na Praia do Bispo em Luanda - Angola, Boletim do Grupo dos Amigos de Luanda, $\mathrm{n}^{\circ} 28$.

FEINZIG, Kristi May (2017) - Tracing Sixteenth Century Beads in South America to Understand their Impact on Indigenous Ritual Practices and Material Culture at the Time of the Spanish Conquest. Master's Thesis. Harvard: Harvard Extension School.

FRANCIS, Peter (1994) - Beads of the World, A Collector's Guide with Price Reference. Atglen: Shiffer Publishing Ltd.

GODINHO, Vitorino Magalhães (1962) - A Economia dos Descobrimentos Henriquinos. Lisboa: Livraria Sá da Costa.

GOMES, Mário Varela (2019) - Braceletes de vidro, Identidade e Cultura. Património Arqueológico de Sharjah (EAU), pp. 126-132. Lisboa: Museu Nacional de Arqueologia, Shar- jah Archaeology Authority, Instituto de Arqueologia e Paleociências da Universidade Nova de Lisboa.

GOMES, Mário Varela; CASIMIRO, Tânia Manuel; GONÇALVES, Joana (2012) - Espólio do Naufrágio da Ponta do Leme Velho (Ilha do Sal, Cabo Verde). Contributo para a Arqueologia da Expansão. Lisboa: Instituto de Arqueologia e Paleociências da Universidade Nova de Lisboa.

GOMES, Mário Varela; GOMES, Rosa Varela (2017) - Vidros do século XVI, do Poço-Cisterna de Silves, Proceedings of the $5^{\text {th }}$ GLASSAC International Conference (Glass Science in Art and Conservation), p. 128. Lisboa: NOVA-FCT Editorial.

GOMES, Mário Varela; GOMES, Rosa Varela (2018) - Garrafa, Três Embaixadas Europeias à China, p. 106 Lisboa: Fundação Oriente.

GOMES, Mário Varela; GOMES, Rosa Varela; CASIMIRO, Tânia Manuel (2019) - Ceramic toys and miniatures from the 16th-18th century found in Lisbon, Europa Postmediavalis 1, pp. 261-268, Archaeopress Publications LTD, Oxford.

GOMES, Mário Varela; GOMES, Rosa Varela; CASIMIRO, Tânia Manuel (2016) - Portuguese faience in Santana Convent, Lisbon. In Rosa Varela GOMES, Tânia Manuel CASIMIRO, Mário Varela GOMES, edit. - Proceedings of the First International Conference of Portuguese Faience ( $16^{\text {th }}$ $19^{\text {th }}$ Centuries), pp. 79-9o. Lisboa: Instituto de Arqueologia e Paleociências da Universidade Nova de Lisboa

GOMES, Mário Varela; GOMES, Rosa Varela; GONÇALVES, Joana (2017) - Objectos produzidos em matérias duras de origem animal, do Convento de Santana, de Lisboa, I Encontro de Arqueologia de Lisboa: Uma Cidade em Escavação, Ana Caessa, Cristina Nozes, Isabel Cameira, Rodrigo Banha da Silva (coord.): 84-105. Lisboa: Centro de Arqueologia de Lisboa / Departamento de Património Cultural / Direção Municipal de Cultura / Câmara Municipal de Lisboa.

GOMES, Mário Varela; GOMES, Rosa Varela; GONÇALVES, Joana (2020) - Artefactos de azeviche no Convento de Santana de Lisboa, Arqueologia \& História, vol. 70, pp. 311-327.

GOMES, Mário; GOMES, Rosa Varela (2007) - Escavações arqueológicas no Convento de Santana, em Lisboa. Resultados Preliminares. Olisipo. Lisboa. II série. 27, pp. 75-92.

GOMES, Mário; GOMES, Rosa Varela; CASIMIRO, Tânia Manuel (2015) - Convents, monasteries and porcelain: a case study of Santana Convent, Lisbon. In Jaume BUXEDA I GARRIGÓS, Marisol MADRID I FERNÁNDEZ, Javier G. IÑANEZ, edit., Global Pottery1. Historical Archaeology and Archaeometry for Societies in Contact, pp. 93-101. British Archaeological Reports, I.S. 2761. Oxford: Archaeopress.

GOMES, Rosa Varela; GOMES, Mário Varela; ALMEIDA, Mariana; BOAVIDA, Carlos; NEVES, Dário; HAMILTON, Kierstin; SANTOS, Carolina (2013) - Convento de Santana (Lisboa). Estudo preliminar do espólio da Fossa 7. In 
José Morais ARNAUD, Andrea MARTINS, César NEVES, coord. - Arqueologia em Portugal. 150 Anos, pp. 1057-1065. Lisboa: Associação dos Arqueólogos Portugueses.

GUTIERREZ, Manuel (2001) - Découverte d'un site funéraire inconnu. La sépulture de Caotinha, Archéologia, $\mathrm{n}^{\circ}$ 377, pp. 46-50.

HAEVERNICK, Thea Elisabeth (1961) - Beiträge zur geschichte des antiken glases. IV - Die aggryperlen = chevron pattern beads = rosettaperlen = star-beads, Jahrbuch des Romisch-Germanischen Zentralmuseums Mainz, vol. 8, pp. 121-138.

HAEVERNICK, Thea Elisabeth (1964) - Contribuição para a história dos vidros antigos, Revista de Guimarães, vol. $\operatorname{LXXIV(3,4),~pp.~290-316,~III~ests.~}$

HARTER, Pierre (1981) - Les perles de verre au Cameron, Arts d'Afrique Noire, vol. 40, pp. 6-22.

HUME, Ivor Noël (1991) - A Guide to Artifacts of Colonial America. New York: First Vintage Books Edition.

JARGSTORF, Sibylle (1995) - Glass Beads from Europe: With Value Guide. Atglen: Shiffer Publishing Ltd.

JOHNSTON, Harry Hamilton (1906) - Liberia, vol. I. London: Hutchinson \& Co.

KARKLINS, Karlis (1985) - Early Amsterdam trade beads, Ornament, vol. 9(2), pp. 36-41.

KARKLINS, Karlis; DUSSUBIEUX, Laure, HANCOCK, Ronald George Vincent (2015) - A $17^{\text {th }}$ century glass bead factory at Hammersmith Embankment, London, England. BEADS: Journal of the Society of Bead Researchers, $\mathrm{n}^{\circ} \mathbf{2 7}$, pp. 16-24.

MATOS, Armando de (1934) - Contas de massa vítrea encontradas em Angola, Trabalhos do $1^{\circ}$ Congresso Nacional de Antropologia Colonial, vol. II, pp. 455-462, Edições da $1^{\underline{a}}$ Exposição Colonial Portuguesa, Porto.

MONOD, Theodore (1952) - Perles anciennes au Portugal et en Afrique Noire Occidentale, Conferencia Internacional dos Africanistas Ocidentais, vol. IV, pp. 387-391, I est. Lisboa: Ministério das Colónias.

PEREIRA, Duarte Pacheco (1892) - Esmeraldo de Situ Orbis. Lisboa: Imprensa Nacional.

PEREIRA, Félix Alves (1927-29) - Jornadas de um curioso pelas margens do Lima, O Archeologo Português, vol. XXVIII, pp. 1-51, 1 est.

PEREIRA, Félix Alves (1933) - Contas policrómicas de pasta vítrea, Portvcale, vol. VI, pp. 24-31, 72-8o, 118-121.

PEREIRA, Félix Alves (1934) - A propósito das contas vítreas policrómicas, Portvcale, vol. VIII, pp. 16-18.

PEREIRA, Gabriel (1910) - Pelos Suburbios e Visinhanças de Lisboa. Lisboa: Livraria Clássica Editora.
PINTO, Rui de Serpa (1932) - Etnografia arqueológica, I. Antigas contas empregues como amuletos, Trabalhos da Sociedade Portuguesa de Antropologia e Etnologia, vol. V(III), pp. 245-250.

PRICE, John Edward (1883) - On aggri beads, The Journal of the Anthropological Institute of Great Britain and Ireland, vol. 12, pp. 64-68.

QUIGGIN, Alison Hingston (1992) - A Survey of Primitive Money. The Beginnings of Currency. Ocala: First Impressions Printing, Inc.

READ, Charles H. (1905) - A necklace of glass beads from West Africa, Man, $\mathrm{n}^{\circ}$ 5(1), pp. 1, 2, pl. A.

REINECKE, Paul Heinrich Adalbert (1929) - Das alter des aggryperlen, Praehistorische Zeitschrift, vol. 2O, pp. 278, 279.

RODRIGUES, Maria da Conceição (1993) - Contribuição para o estudo de contas de origem mediterrânea recolhidas em Angola, Mediterrâneo, nº 3, pp. 349-364.

RODRIGUES, Maria da Conceição (1997) - Contribuição para o estudo de contas de vidro de origem mediterrânica recolhidas na baixa pombalina de Lisboa, II Colóquio Temático Lisboa Ribeirinha. Lisboa, Câmara Municipal de Lisboa.

RODRIGUES, Maria da Conceição (2003) - The importance of the long glass beads of Mediterranean origin collected in the "Baixa Pombalina", Lisbon. Contribution to the study of the "Nueva Cadiz" type beads, Zephyrus, vol. 56 , pp. 207-233.

RODRIGUES, Maria da Conceição (2014) - As "Contas Longas" de Vidro como Elemento de Identidade dos Africanos no Passado Histórico e Cultural de Lisboa. De Meados do Século XV ao Terramoto de 1755. Porto: Universidade do Porto Editorial.

SILVA, Rosas da (1934) - Conta de vidro policromo encontrada no Castro de Sabroso, Revista de Guimarães, vol. XLIV(1), pp. 35-38.

SMITH, Marvin, T.; GOOD, Mary Elizabeth (1982) - Early Sixteenth Century Glass Beads in the Spanish Colonial Trade. Greenwood, Mississipi: Cottonlandia Museum Publications.

SOUSA, José Maria Cordeiro de (1954) - Grandes contas vítreas multicolores do Museu da Sociedade de Geografia de Lisboa, Boletim da Sociedade de Geografia de Lisboa, $72^{\underline{\underline{a}}}$ série, $\mathrm{n}^{\mathrm{os}} 1-3$, pp. 115-117, I est.

SOUSA, José Maria Cordeiro de (1955) - As grandes contas vítreas multicolores do Museu da Sociedade de Geografia de Lisboa, Revista de Guimarães, vol. LXV, pp. 142-144, 1 est.

SOUSA, Luís Rebelo de (1967) - Moedas de Angola. Luanda: Banco de Angola.

TEMPLE, Richard Carnac (1899) - Beginnings of currency, The Journal of the Anthropological Institute of Great Britain and Ireland, vol. 29 (1, 2), pp. 99-122. 
TISCHLER, Otto (1886) - Ueber aggry-perlen und über die Herstellung farbiger gläser im alterthume, Bericht über die in den Sitzungen der Physikalisch-Ökonomischen Gesellschaft zu Königsberg in Preussen, vol. 27, pp. 5-15.

TORRES, Andreia Martins (2007) - Contas exumadas na intervenção arqueológica do Palácio dos Marqueses de Marialva - Uma tipologia usada no trato colonial, Anais de História de Além-Mar, vol. VIII, pp. 181-237.

TOUGARD, A. (1897)-Vénitien receu à faire des patenôtres en France, en verre esmaillé, Bulletin de la Commission des Antiquités de la Seine-Inférieure, vol. 10, pp. 427-430.
VALENTE, Francisca Pulido; GOMES, Rosa Varela; GOMES, Mário Varela; COUTINHO, Inês; MEDICI, Teresa; VILARIQUES, Márcia (2019) - Renaissance Millefiori glass: the Portuguese case study, Recent Advances in Glass and Ceramics Conservation, pp. 217-221. London: British Museum.

VEIGA, Sebastião Philippes Martins Estácio da (1891) - Antiguidades Monumentaes do Algarve. Tempos Prehistóricos, vol. IV. Lisboa: Imprensa Nacional.

\begin{tabular}{|l|l|l|l|l|}
\hline Referência & Unid. & Descrição (anéis) & $\varnothing(\mathrm{m})$ & Esp. (m) \\
\hline CS/F6-1658 & 1 & $\begin{array}{l}\text { frag., de vidro negro, opaco, com protuberâncias em ambas laterais do aro, } \\
\text { possível anel de martírio }\end{array}$ & 0,0180 & 0,0022 \\
\hline CS/F6-1657 & 1 & vidro negro, opaco, com pequeno elemento esférico & 0,0120 & 0,0019 \\
\hline CS/F6-1649 & 1 & vidro negro, opaco, com enrolamento oblíquo e pequeno elemento esférico & 0,0135 & 0,0019 \\
\hline CS/F6-1650 & 1 & $\begin{array}{l}\text { frag., de vidro negro, opaco, de secção conc./conv., com flor de oito pétalas } \\
(\varnothing=0,0080 \text { m })\end{array}$ & 0,0150 & 0,0047 \\
\hline CS/P2-4 & 1 & $\begin{array}{l}\text { vidro azul índigo, translúcido, secção oval, e motivo floral de oito pétalas } \\
(\varnothing=0,0083 \text { m) }\end{array}$ & 0,0190 & 0,0033 \\
\hline CS/Zona F-1 & 1 & frag., de vidro negro, opaco, com secção circular & 0,0200 & 0,0024 \\
\hline
\end{tabular}

Tabela 1 - Convento de Santana, Lisboa. Anéis de vidro.

\begin{tabular}{|l|l|l|l|l|}
\hline Referência & Unid. & Descrição (braceletes) & $\varnothing(\mathrm{m})$ & esp. (m) \\
\hline CS/Q219-21 & I & frag., oca, de vidro incolor, transparente e secção circular & 0,0800 & - \\
\hline CS/F6-1864 & 1 & frag., oca, de vidro azul translúcido, de secção circular & 0,080o & 0,0084 \\
\hline CS/F1o-1 & I & frag., oca, de vidro incolor, transparente, com secção circular & 0,0600 & 0,0088 \\
\hline CS/P-240 & 1 & frag., maciça, de vidro azul-turquesa, translúcido e secção oval & 0,0158 & 0,0075 \\
\hline
\end{tabular}

Tabela 2 - Convento de Santana, Lisboa. Braceletes de vidro. 


\begin{tabular}{|c|c|c|c|c|c|c|}
\hline Referência & Unid. & Descrição (missangas) & Forma & $\varnothing(\mathrm{m})$ & Altura (m) & $\varnothing$ do orif. (m) \\
\hline $\begin{array}{l}\text { CS/Sep.7-2 } \\
\text { CS/Sep.7-3 }\end{array}$ & 2 & vidro branco, translúcido & esférica achat. & $\begin{array}{l}0,0041 \\
0,0032\end{array}$ & $\begin{array}{l}0,0025 \\
0,0020\end{array}$ & \\
\hline $\begin{array}{l}\text { CS/Sep.7-4 } \\
\text { a } 156\end{array}$ & 153 & vidro azul, translúcido & esférica achat. & $\begin{array}{l}0,0032 \\
0,0031 \\
0,0028 \\
0,0030\end{array}$ & $\begin{array}{l}0,0024 \\
0,0028 \\
0,0017 \\
0,0014\end{array}$ & $\begin{array}{l}0,0012 \\
0,0013 \\
0,0013 \\
0,0009\end{array}$ \\
\hline CS/Sep.3B-3 & 15 & $\begin{array}{l}\text { vidro branco, opaco, unidas por } \\
\text { elos metálicos (prata?) formando } \\
\text { corrente }\end{array}$ & esférica achat. & $\begin{array}{l}\text { c. o, } 0035 \\
-0,0040 \\
\text { elo } 0,0008\end{array}$ & $\begin{array}{l}\text { o,o030 } \\
-0,0036 \\
\text { o,oogo } \\
\text { c. total o,110o }\end{array}$ & \\
\hline $\begin{array}{l}\text { CS/Sep.18-1 } \\
\text { a } 142\end{array}$ & $\begin{array}{l}71 \\
69 \\
2\end{array}$ & vidro branco, opaco & $\begin{array}{l}\text { esférica achat. } \\
\text { cilíndrica } \\
\text { pequena }\end{array}$ & $\begin{array}{l}0,0041 \\
0,0037 \\
0,0027\end{array}$ & $\begin{array}{l}\mathrm{O}, \mathrm{OO} 25 \\
\mathrm{O}, \mathrm{OO} 34 \\
\mathrm{O}, \mathrm{OO} 23\end{array}$ & $\begin{array}{l}0,0015 \\
0,0014 \\
0,0012\end{array}$ \\
\hline $\begin{array}{l}\text { CS/Sep.4-1 } \\
\text { a } 16 \\
\text { CS/Sep.4-17 } \\
\text { a } 54\end{array}$ & $\begin{array}{l}16 \\
38\end{array}$ & vidro branco, opaco & $\begin{array}{l}\text { cilíndrica } \\
\text { esférica achat. }\end{array}$ & $\begin{array}{l}0,0036 \\
0,0041\end{array}$ & $\begin{array}{l}0,0044 \\
0,0032\end{array}$ & $\begin{array}{l}0,0013 \\
0,0012\end{array}$ \\
\hline $\begin{array}{l}\text { CS/Sep.5B-1 } \\
\text { e } 2\end{array}$ & 2 & vidro azul translúcido & cilíndrica & $\begin{array}{l}0,0062 \\
0,0059\end{array}$ & $\begin{array}{l}0,0040 \\
0,0048\end{array}$ & $\begin{array}{l}0,0020 \\
0,0019\end{array}$ \\
\hline $\begin{array}{l}\text { CS/Sep.5B-3 } \\
\text { a } 12\end{array}$ & 10 & vidro branco opaco & cilíndrica & 0,0036 & 0,0038 & 0,0012 \\
\hline $\begin{array}{l}\text { CS/Oss.4-11 } \\
\text { a } 105\end{array}$ & $\begin{array}{l}87 \\
8\end{array}$ & vidro branco translúcido (rosário ?) & $\begin{array}{l}\text { esférica achat. } \\
\text { cilíndrica }\end{array}$ & $\begin{array}{l}0,0030 \\
0,0032\end{array}$ & $\begin{array}{l}0,0028 \\
0,0035\end{array}$ & $\begin{array}{l}0,0010 \\
0,0014\end{array}$ \\
\hline $\mathrm{CS} / \mathrm{P}-228$ & 1 & vidro azul, translúcido & esférica achat. & 0,0044 & 0,0029 & 0,0012 \\
\hline $\mathrm{CS} / \mathrm{P}-229$ & 1 & vidro azul, translúcido & esférica achat. & 0,0048 & 0,0042 & 0,0020 \\
\hline $\mathrm{CS} / \mathrm{P}-230$ & 1 & vidro branco, opaco & cilíndrica & 0,0044 & 0,0034 & 0,0018 \\
\hline $\mathrm{CS} / \mathrm{P}-232$ & 1 & vidro verde água, translúcido & esférica achat. & 0,0046 & 0,0029 & o,0011 \\
\hline $\begin{array}{l}\mathrm{CS} / \mathrm{Q}_{3} \mathrm{O} 6 / \\
\mathrm{C}_{2}-5\end{array}$ & 1 & vidro verde azeitona, translúcido & cilíndrica & 0,0031 & 0,0028 & 0,0009 \\
\hline CS/Oss.4-7 & 1 & vidro branco, opaco & cilíndrica & 0,0058 & 0,0049 & 0,0012 \\
\hline CS/Oss.4-8 & 1 & vidro branco, opaco & cilíndrica & 0,0056 & 0,0047 & 0,0014 \\
\hline $\mathrm{CS} / \mathrm{F} 6-1653$ & 1 & vidro branco, opaco & esférica & 0,0047 & 0,0045 & 0,0011 \\
\hline CS/Oss.4-10 & 1 & vidro branco, opaco & esférica & 0,0030 & 0,0025 & 0,0009 \\
\hline CS/Q219-4 & 1 & vidro branco, opaco & esférica & 0,0023 & 0,0025 & 0,0008 \\
\hline
\end{tabular}

Tabela 3 - Convento de Santana, Lisboa. Missangas (contas de muito pequenas dimensões, seed beads), de vidro.

\begin{tabular}{|l|l|l|l|l|l|l|}
\hline Referência & Unid. & Descrição & Forma & $\varnothing(\mathrm{m})$ & Altura (m) & $\varnothing$ do orif. (m) \\
\hline CS/Q219-27 & 2 & $\begin{array}{l}\text { duas contas fundidas, de vidro } \\
\text { incolor, transparente, com onze linhas } \\
\text { brancas cada (o,ooo9 m) }\end{array}$ & esférica achat. & $\begin{array}{l}\text { 0,0049 } \\
\text { 0,0060 }\end{array}$ & $\begin{array}{l}\text { 0,0044 } \\
\text { 0,0051 }\end{array}$ & $\begin{array}{l}\text { 0,0012 } \\
\text { 0,0012 }\end{array}$ \\
\hline CS/Q219-2 & 1 & $\begin{array}{l}\text { conta, de vidro incolor, transparente, } \\
\text { com 11 linhas de cor branca, opaca } \\
\text { (o, ooo4 m). apresenta-se deformada, } \\
\text { talvez por acção do calor }\end{array}$ & cilíndrica & 0,0070 & 0,0109 & 0,0009 \\
\hline CS/Q219-1 & 1 & $\begin{array}{l}\text { conta, de vidro incolor, transparente, } \\
\text { com 12 linhas transversais de cor } \\
\text { branca, opaca (o,ooo4 m) }\end{array}$ & cilíndrica & 0,0059 & 0,0089 & 0,0018 \\
\hline
\end{tabular}

Tabela 4 - Convento de Santana, Lisboa. Contas de vidro incolor, transparente, com linhas brancas. 


\begin{tabular}{|c|c|c|c|c|c|c|}
\hline Referência & Unid. & Descrição & Forma & $\varnothing(\mathrm{m})$ & Altura $(\mathrm{m})$ & $\varnothing$ do orif. $(\mathrm{m})$ \\
\hline $\mathrm{CS} / \mathrm{P}_{2}-10$ & 1 & conta, de vidro preto, opaco, brilhante & esférica & 0,0109 & 0,0092 & 0,0029 \\
\hline $\mathrm{CS} / \mathrm{P}_{2}-16$ & 1 & conta, de vidro preto, opaco, brilhante & esférica achat. & 0,0103 & 0,0083 & 0,0024 \\
\hline $\mathrm{CS} / \mathrm{P}-94$ & 1 & conta, de vidro preto, opaco, brilhante & esférica achat. & 0,0084 & 0,0051 & 0,0029 \\
\hline $\mathrm{CS} / \mathrm{P}_{2}-6$ & 1 & conta, de vidro preto, opaco, brilhante & esférica achat. & 0,0124 & 0,0095 & 0,0035 \\
\hline $\mathrm{CS} / \mathrm{P}_{2-9}$ & 1 & conta, frag., de vidro preto, opaco, brilhante & esférica & 0,0114 & 0,0112 & 0,0027 \\
\hline $\mathrm{CS} / \mathrm{P}_{2-7}$ & 1 & conta, de vidro negro, opaco, brilhante & esférica achat. & :0,009o & 0,0079 & 0,0019 \\
\hline
\end{tabular}

Tabela 5-Convento de Santana, Lisboa. Contas de viro opaco de cor negra.

\begin{tabular}{|c|c|c|c|c|c|c|}
\hline Referência & Unid. & Descrição (contas tubulares) & Forma & $\begin{array}{l}\varnothing \\
(\mathrm{m})\end{array}$ & $\begin{array}{l}\text { Altura } \\
(\mathrm{m})\end{array}$ & $\begin{array}{l}\varnothing \text { do } \\
\text { orif. (m) }\end{array}$ \\
\hline $\mathrm{CS} / \mathrm{P}-231$ & 1 & vidro azul-turquesa, translúcido, de secção circular & tubular lisa & 0,0075 & 0,0095 & 0,0023 \\
\hline CS/Q224-1 & 1 & vidro azul-turquesa, translúcido, de secção circular & tubular lisa & 0,0064 & 0,0179 & 0,0025 \\
\hline $\begin{array}{l}\text { CS/ } \\
\text { Oss.4-106 }\end{array}$ & 1 & $\begin{array}{l}\text { frag., de vidro azul-turquesa, translúcido, } \\
\text { de secção circular }\end{array}$ & tubular lisa & 0,0064 & 0,0144 & 0,0028 \\
\hline $\mathrm{CS} / \mathrm{P}_{2}-45$ & 1 & $\begin{array}{l}\text { vidro azul água, translúcido, de secção circular, } \\
\text { biselada em ambas extremidades }\end{array}$ & tubular lisa & 0,0067 & 0,0209 & 0,0029 \\
\hline $\mathrm{CS} / \mathrm{P}_{2-2}$ & 1 & vidro azul-turquesa translúcido, de secção circular & tubular lisa & 0,0073 & 0,0314 & 0,0030 \\
\hline CS/P-93 & 1 & vidro azul-turquesa, opaca, de secção circular & tubular lisa & 0,0059 & 0,0126 & 0,0026 \\
\hline $\begin{array}{l}\text { CS/Q155/ } \\
C_{3-2}\end{array}$ & 1 & $\begin{array}{l}\text { frag., de vidro azul-turquesa / branco / } \\
\text { azul-turquesa, translúcido, de secção quadrangular }\end{array}$ & tubular lisa & 0,0073 & 0,0202 & 0,0022 \\
\hline $\mathrm{CS} / \mathrm{P}_{2}-1$ & 1 & $\begin{array}{l}\text { vidro azul-turquesa / branco / azul-turquesa, } \\
\text { translúcido, de secção quadrangular, com os cantos } \\
\text { ligeiramente facetados numa das extremidades }\end{array}$ & tubular lisa & 0,0084 & $0,055^{2}$ & 0,0041 \\
\hline $\begin{array}{l}\text { CS/Q173/ } \\
\text { C2-1 }\end{array}$ & 1 & $\begin{array}{l}\text { frag., de vidro azul-turquesa / branco / azul- } \\
\text { turquesa, translúcido, de secção trapezoidal, com } \\
\text { os cantos da extremidade existente facetados }\end{array}$ & tubular lisa & 0,0153 & 0,0289 & 0,0046 \\
\hline $\begin{array}{l}\mathrm{CS} / \mathrm{Q}_{231} / \\
\mathrm{C} 1-1\end{array}$ & 1 & $\begin{array}{l}\text { frag., de vidro azul-turquesa / branco / azul- } \\
\text { turquesa, translúcido, com secção quadrangular }\end{array}$ & tubular lisa & 0,0085 & 0,0239 & 0,0028 \\
\hline $\begin{array}{l}\mathrm{CS} / \mathrm{Q}_{180} / \\
\mathrm{C} 2-2\end{array}$ & 1 & $\begin{array}{l}\text { frag., de vidro azul-turquesa / branco / azul-turquesa, } \\
\text { translúcido, de secção quadrangular e cantos } \\
\text { facetados numa das extremidades }\end{array}$ & tubular lisa & 0,0109 & 0,0185 & 0,0046 \\
\hline $\begin{array}{l}\mathrm{CS} / \mathrm{Q} 18 \mathrm{o} / \\
\mathrm{C} 2-3\end{array}$ & 1 & $\begin{array}{l}\text { frag., de vidro azul-turquesa / branco / azul-turquesa, } \\
\text { translúcido, de secção quadrangular }\end{array}$ & tubular lisa & 0,0135 & & 0,0069 \\
\hline CS/FI1-2 & 1 & $\begin{array}{l}\text { vidro azul-turquesa / branco / azul-turquesa, } \\
\text { translúcido, de secção quadrangular, com os cantos } \\
\text { de uma das extremidades facetados }\end{array}$ & tubular torsa & 0,0092 & 0,0302 & 0,0034 \\
\hline $\mathrm{CS} / \mathrm{P}_{2}-44$ & 1 & $\begin{array}{l}\text { vidro azul-turquesa / branco / azul-turquesa, } \\
\text { translúcido, de secção quadrangular, com os cantos } \\
\text { de uma das extremidades facetados }\end{array}$ & tubular torsa & 0,0092 & 0,0241 & 0,0030 \\
\hline $\mathrm{CS} / \mathrm{Q}_{3} \mathrm{O}^{-1}$ & 1 & $\begin{array}{l}\text { vidro azul-turquesa / branco / azul-turquesa, } \\
\text { translúcido, de secção quadrangular, com os cantos } \\
\text { de uma das extremidades facetados }\end{array}$ & tubular torsa & 0,0092 & 0,0309 & 0,0033 \\
\hline $\begin{array}{l}\text { CS/Q113/ } \\
\text { C1-1 }\end{array}$ & 1 & $\begin{array}{l}\text { frag., de vidro azul-turquesa / branco / azul-turquesa, } \\
\text { translúcido, de secção quadrangular, com os cantos } \\
\text { de uma das extremidades facetados }\end{array}$ & tubular torsa & 0,0107 & 0,0251 & 0,0036 \\
\hline CS/Q219-16 & 1 & $\begin{array}{l}\text { dois frags, de secção circular, perfurada, de vidro azul } \\
\text { índigo, translúcido, com } 3 \text { linhas brancas }\end{array}$ & cilindrica & 0,0059 & - & 0,0027 \\
\hline $\mathrm{CS} / \mathrm{P}_{2}-47$ & 1 & $\begin{array}{l}\text { frag., de vidro azul-turquesa translúcido, com três } \\
\text { listas transversais de cor bordeaux/castanha, opaca, } \\
\text { de secção circular }\end{array}$ & tubular lisa & 0,0064 & 0,0307 & 0,0029 \\
\hline CS/Q219-19 & 1 & conta, de vidro azul translúcido & tubular lisa & 0,0026 & 0,0158 & 0,0012 \\
\hline
\end{tabular}

Tabela 6 - Convento de Santana, Lisboa. Contas tubulares de cor azul-turquesa (Nueva Cádiz). 


\begin{tabular}{|l|l|l|l|l|l|l|}
\hline Referência & Unid. & Descrição & Forma & $\varnothing(\mathrm{m})$ & Altura (m) & $\varnothing$ do orif. (m) \\
\hline CS/P2-46 & 1 & $\begin{array}{l}\text { conta, de vidro verde esmeralda, } \\
\text { translúcido, de secção quadrangular }\end{array}$ & tubular torsa & 0,0066 & 0,0392 & 0,0021 \\
\hline
\end{tabular}

Tabela 7 - Convento de Santana, Lisboa. Conta tubular, torsa, de vidro de cor verde esmeralda.

\begin{tabular}{|l|l|l|l|l|l|l|}
\hline Referência & Unid. & Descrição & Forma & $\varnothing(\mathrm{m})$ & Altura (m) & $\varnothing$ do orif. (m) \\
\hline CS/Q219-6 & 1 & $\begin{array}{l}\text { frag., de tipo chevron, de vidro } \\
\text { azul-turquesa transl. / branco opaco / } \\
\text { azul-turquesa transl. / branco opaco / } \\
\text { bordeaux opaco / azul índigo } \\
\text { translúcido }\end{array}$ & $\begin{array}{l}\text { cilíndrica, } \\
\text { facetada nos } \\
\text { topos }\end{array}$ & 0,0220 & 0,0192 & 0,0036 \\
\hline
\end{tabular}

Tabela 8 - Convento de Santana, Lisboa. Conta chevron.

\begin{tabular}{|l|l|l|l|l|l|l|}
\hline Referência & Unid. & Descrição & Forma & $\varnothing(\mathrm{m})$ & Altura (m) & $\varnothing$ do orif. (m) \\
\hline $\begin{array}{l}\text { CS/Q305/ } \\
\text { C2-5 }\end{array}$ & 1 & $\begin{array}{l}\text { conta, de vidro vermelho e negro, } \\
\text { opaco }\end{array}$ & esférica achat. & 0,0058 & 0,0046 & 0,0010 \\
\hline
\end{tabular}

Tabela 9 - Convento de Santana, Lisboa. Conta de vidro de cor vermelha com o interior de cor negra.

\begin{tabular}{|c|c|c|c|c|c|c|}
\hline Referência & Unid. & Descrição & Forma & $\varnothing(\mathrm{m})$ & Altura (m) & $\varnothing$ do orif. (m) \\
\hline $\begin{array}{l}C S / Q 219-22 \\
\text { e } 23 \\
C S / Q 219-24\end{array}$ & 3 & $\begin{array}{l}\text { contas, de vidro de cor bordeaux, } \\
\text { opaco, com quatro linhas brancas }\end{array}$ & $\begin{array}{l}\text { esférica achat. } \\
\text { esférica }\end{array}$ & $\begin{array}{l}0,0068 \\
0,0051\end{array}$ & $\begin{array}{l}0,0055 \\
0,0054\end{array}$ & $\begin{array}{l}0,0012 \\
0,0008\end{array}$ \\
\hline $\begin{array}{l}C S / Q_{219-25} \\
C S / Q_{219-26}\end{array}$ & 2 & $\begin{array}{l}\text { conta, de vidro de cor bordeaux, } \\
\text { opaco, com quatro linhas brancas }\end{array}$ & $\begin{array}{l}\text { esférica } \\
\text { cilíndrica }\end{array}$ & $\begin{array}{l}0,0049 \\
0,0033\end{array}$ & $\begin{array}{l}0,0042 \\
0,0038\end{array}$ & $\begin{array}{l}0,0014 \\
0,0013\end{array}$ \\
\hline $\mathrm{CS} / \mathrm{Q} 219-28$ & 3 & $\begin{array}{l}\text { três contas fundidas, de vidro de cor } \\
\text { bordeaux, opaco, com quatro linhas } \\
\text { brancas cada (o,0017 m) }\end{array}$ & esférica achat. & 0,0067 & 0,0048 & 0,0017 \\
\hline $\begin{array}{l}C S / Q 219-29 \\
\text { e } 30 \\
C S / Q 219-31 \\
\text { e } 32\end{array}$ & 10 & $\begin{array}{l}\text { dois pares e dois conjuntos de três } \\
\text { contas fundidas, de vidro de cor } \\
\text { bordeaux, opaco, com quatro linhas } \\
\text { brancas cada }\end{array}$ & $\begin{array}{l}\text { esférica achat. } \\
\text { esféricas }\end{array}$ & $\begin{array}{l}0,0051 \\
0,0045\end{array}$ & $\begin{array}{l}0,0032 \\
0,0044\end{array}$ & $\begin{array}{l}0,0014 \\
0,0010\end{array}$ \\
\hline
\end{tabular}

Tabela 1o - Convento de Santana, Lisboa. Contas de vidro de cor vermelha (bordeaux), com listas brancas.

\begin{tabular}{|l|l|l|l|l|l|l|}
\hline Referência & Unid. & Descrição & Forma & $\varnothing(\mathrm{m})$ & Altura (m) & $\varnothing$ do orif. (m) \\
\hline CS/Oss.4-6 & 1 & $\begin{array}{l}\text { missanga, de vidro de cor âmbar, } \\
\text { translúcido }\end{array}$ & cilíndrica & 0,0062 & 0,0047 & 0,0028 \\
\hline CS/F6-1655 & 1 & $\begin{array}{l}\text { missanga, de vidro de cor âmbar } \\
\text { vermelho, translúcido }\end{array}$ & cilíndrica & 0,0066 & 0,0040 & 0,0019 \\
\hline $\begin{array}{l}\text { CS/Jardim } \\
\text { N-1 }\end{array}$ & 1 & $\begin{array}{l}\text { conta, de vidro de cor âmbar, } \\
\text { translúcido }\end{array}$ & esférica & 0,0128 & 0,0124 & 0,0031 \\
\hline CS/P-89 & 1 & $\begin{array}{l}\text { conta, de vidro de cor âmbar, } \\
\text { translúcido }\end{array}$ & esférica achat. & 0,1000 & 0,0074 & 0,0039 \\
\hline
\end{tabular}

Tabela 11 - Convento de Santana, Lisboa. Contas de vidro de cor âmbar. 


\begin{tabular}{|l|l|l|l|l|l|l|}
\hline Referência & Unid. & Descrição & Forma & $\varnothing(\mathrm{m})$ & Altura (m) & $\varnothing$ do orif. (m) \\
\hline CS/Q219-4 & 2 & $\begin{array}{l}\text { vidro bordeaux, opaco, com pequenas } \\
\text { aplicações de vidro amarelo, em relevo }\end{array}$ & esférica & $\begin{array}{l}\text { 0,0107 } \\
\text { 0,006o }\end{array}$ & $\begin{array}{l}\text { 0,0100 } \\
\text { o, 0050 }\end{array}$ & \\
\hline
\end{tabular}

Tabela 12 - Convento de Santana, Lisboa. Contas ocas com aplicações de vidro amarelo.

\begin{tabular}{|l|l|l|l|l|l|l|}
\hline Referência & Unid. & Descrição & Forma & $\varnothing(\mathrm{m})$ & Altura (m) & $\varnothing$ do orif. (m) \\
\hline CS/Q219-35 & 1 & $\begin{array}{l}\text { vidro branco, opaco, com secção circular } \\
\text { e três conjuntos de três incisões douradas }\end{array}$ & tubular lisa & 0,0053 & 0,0139 & 0,0016 \\
\hline CS/Q219-3 & 1 & $\begin{array}{l}\text { vidro branco, opaco, com secção circular } \\
\text { e três conjuntos de três incisões douradas }\end{array}$ & tubular lisa & 0,0054 & 0,0337 & 0,0020 \\
\hline
\end{tabular}

Tabela 13 - Convento de Santana, Lisboa. Contas com decoração dourada.

\begin{tabular}{|c|c|c|c|c|c|c|}
\hline Referência & Unid. & Descrição & Forma & $\varnothing(\mathrm{m})$ & Altura (m) & $\varnothing$ do orif. (m) \\
\hline $\begin{array}{l}\text { CS/Sep.7- } \\
-157 \text { a } 174\end{array}$ & 18 & vidro incolor, translúcido & prismática & $\begin{array}{l}0,0029 \\
0,0041\end{array}$ & 0,0049 & 0,0013 \\
\hline $\begin{array}{l}\text { CS/ } \\
\text { Q219-20 }\end{array}$ & 1 & $\begin{array}{l}\text { vidro incolor, transparente, em forma } \\
\text { de gota, com orifício descentrado }\end{array}$ & oval & $\begin{array}{l}0,0077 x \\
0,0101\end{array}$ & $\begin{array}{l}\text { esp. máx. } \\
\text { o,oo70 }\end{array}$ & $\begin{array}{l}0,0016 x \\
0,0021\end{array}$ \\
\hline $\mathrm{CS} / \mathrm{Q}_{307-3}$ & 1 & vidro azul cobalto, transparente & $\begin{array}{l}\text { bi-tronco- } \\
\text {-piramidal }\end{array}$ & 0,0073 & 0,0084 & o,0019 \\
\hline CS/P-91 & 1 & $\begin{array}{l}\text { frag., de vidro negro, opaco, oval, plana } \\
\text { numa face e facetada na outra, com três } \\
\text { perfurações transversais }\end{array}$ & facetada & $\begin{array}{l}0,0254 x \\
0,0128\end{array}$ & 0,0068 & 0,0012 \\
\hline CS/F6-1659 & 1 & $\begin{array}{l}\text { vidro incolor, transparente, secção } \\
\text { quadrangular }\end{array}$ & tubular & 0,0053 & 0,0495 & 0,0021 \\
\hline $\begin{array}{l}\mathrm{CS} / \\
\text { Q219-34 }\end{array}$ & 1 & frag., de vidro verde água, translúcido & periforme & 0,0062 & 0,0116 & \\
\hline
\end{tabular}

Tabela 14 - Convento de Santana, Lisboa. Outras contas de vidro.

\begin{tabular}{|c|c|c|c|c|c|c|}
\hline Referência & Unid. & Descrição & Forma & $\varnothing(\mathrm{m})$ & Altura (m) & $\varnothing$ do orif. (m) \\
\hline $\mathrm{CS} / \mathrm{Q} 219-33$ & 65 & $\begin{array}{l}\text { canas, frag., três deles fundidos e } \\
\text { deformados, perfuradas, de vidro } \\
\text { vermelho, opaco, com } 4 \text { linhas } \\
\text { brancas cada }\end{array}$ & cana & $\begin{array}{l}0,0025 \\
0,0035 \\
0,0040 \\
0,0046 \\
0,0057\end{array}$ & & $\begin{array}{l}0,0012 \\
0,0015 \\
0,0020 \\
0,0030 \\
0,0022\end{array}$ \\
\hline $\mathrm{CS} / \mathrm{Q}_{219-18}$ & 1 & $\begin{array}{l}\text { cana, frag., de secção circular, de vidro } \\
\text { bordeaux, opaco, com três linhas brancas }\end{array}$ & vara & 0,0020 & 0,0217 & \\
\hline $\mathrm{CS} / \mathrm{Q} 219-17$ & 1 & vara, frag., de vidro azul / branco / azul & vara & 0,0042 & 0,0151 & \\
\hline $\begin{array}{l}\mathrm{CS} / \mathrm{Q}_{1} 82 / \\
\mathrm{C} 2-3\end{array}$ & 1 & vara, de vidro incolor, transparente & vara & 0,0047 & 0,0596 & \\
\hline $\begin{array}{l}\text { CS/ } \\
\text { Q219-36 }\end{array}$ & 1 & $\begin{array}{l}\text { vara, frag., de vidro incolor, transparente, } \\
\text { decorada com listas de cor branca, em } \\
\text { espiral, alternando uma lista isolada com } \\
\text { conjunto de quatro listas }\end{array}$ & vara & 0,0037 & 0,0277 & \\
\hline
\end{tabular}

Tabela 15 - Convento de Santana, Lisboa. Canas e varas de vidro. 


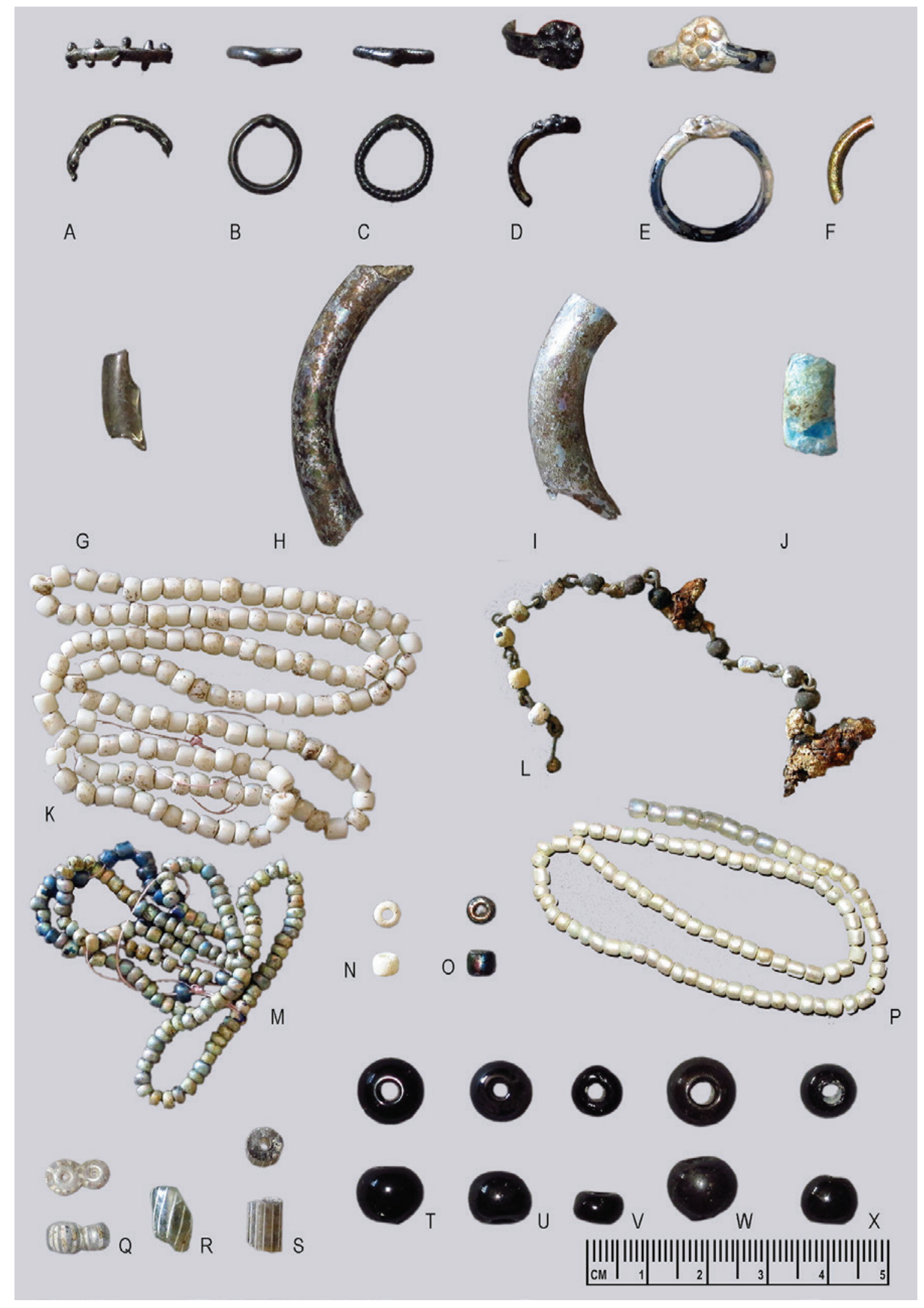

Figura 1 - Convento de Santana, Lisboa. Anéis (A. CS/F6-1658; B. CS/F6-1657; C. CS/F6-1649; D. CS/F6-1650; E. CS/P2-4; F. CS/Zona F-1), braceletes (G. CS/Q219-21; H. CS/F6-1864; I. CS/F1O-1; J. CS/P-24O), missangas (K. CS/Sep.18-1 a 142; L. CS/Sep.3B-3; M. CS/Sep.7-4 a 156; N. CS/P-229; O. CS/P-23O; P. CS/Oss.4-11 a 105), contas de vidro incolor, transparente, com linhas brancas (Q. CS/Q219-27; R. CS/Q219-2; S. CS/Q219-1), contas de vidro opaco de cor negra (T. CS/P2-10; U. CS/P2-16; V. CS/P-94; W. CS/P2-6; X. CS/P2-7) (fotos J. Gonçalves). 


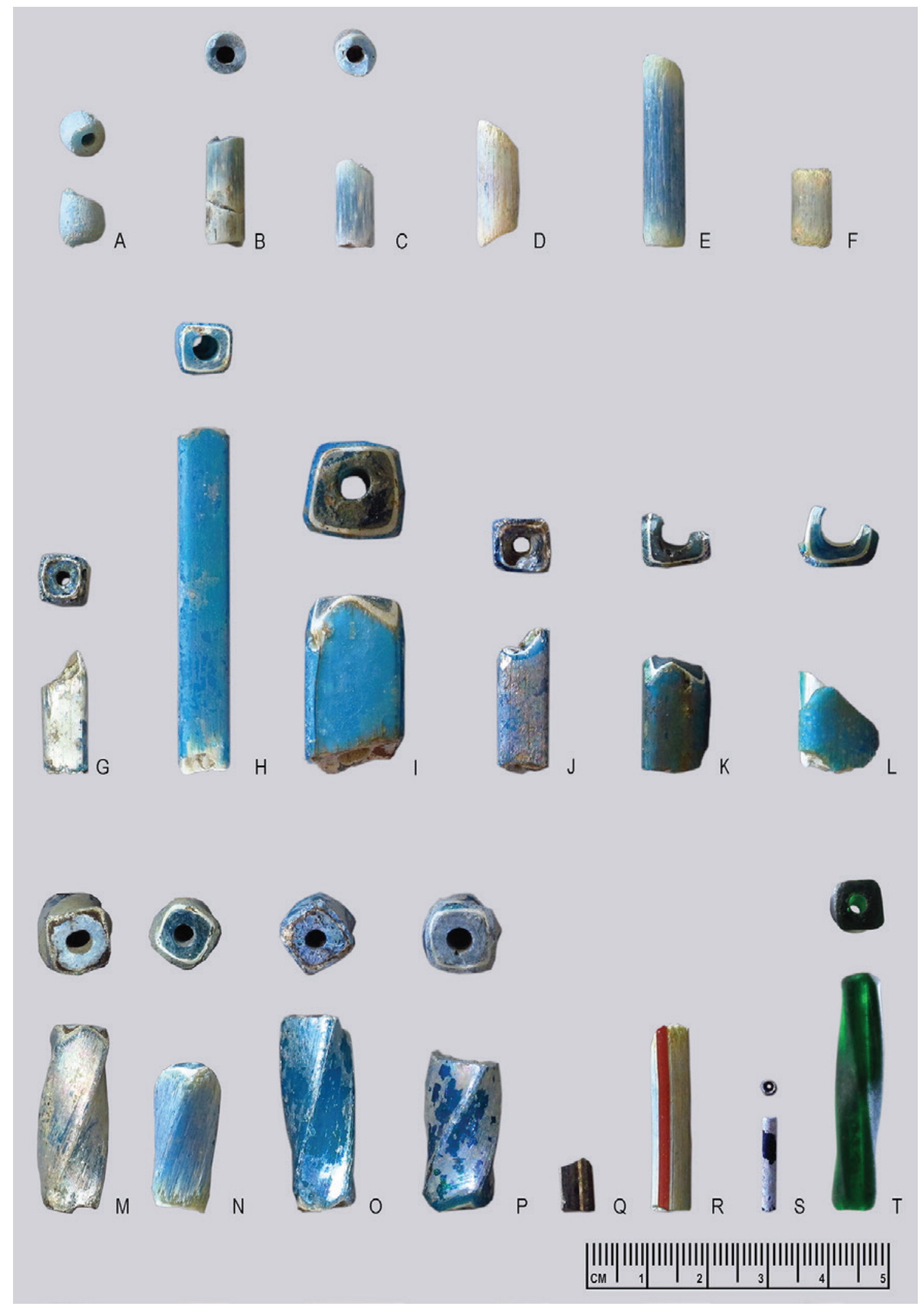

Figura 2 - Convento de Santana, Lisboa. Contas tubulares, de cor azul-turquesa (Nueva Cádiz) (A. CS/P-231; B. CS/Q224-1; C. CS/Oss.4-106; D. CS/P2-45; E. CS/P2-2; F. CS/P-93; G. CS/Q155/C2-2; H. CS/P2-1; I. CS/Q173/ C2-1; J. CS/Q231/C1-1; K. CS/Q180/C2-2; L. CS/Q180/C2-1; M. CS/F11-2; N. CS/P2-44; O. CS/Q304-1; P. CS/ Q113/C1-1; Q. CS/Q219-16; R. CS/P2-47; S. CS/Q219-19) e verde esmeralda (T. CS/P2-46) (fotos J. Gonçalves). 


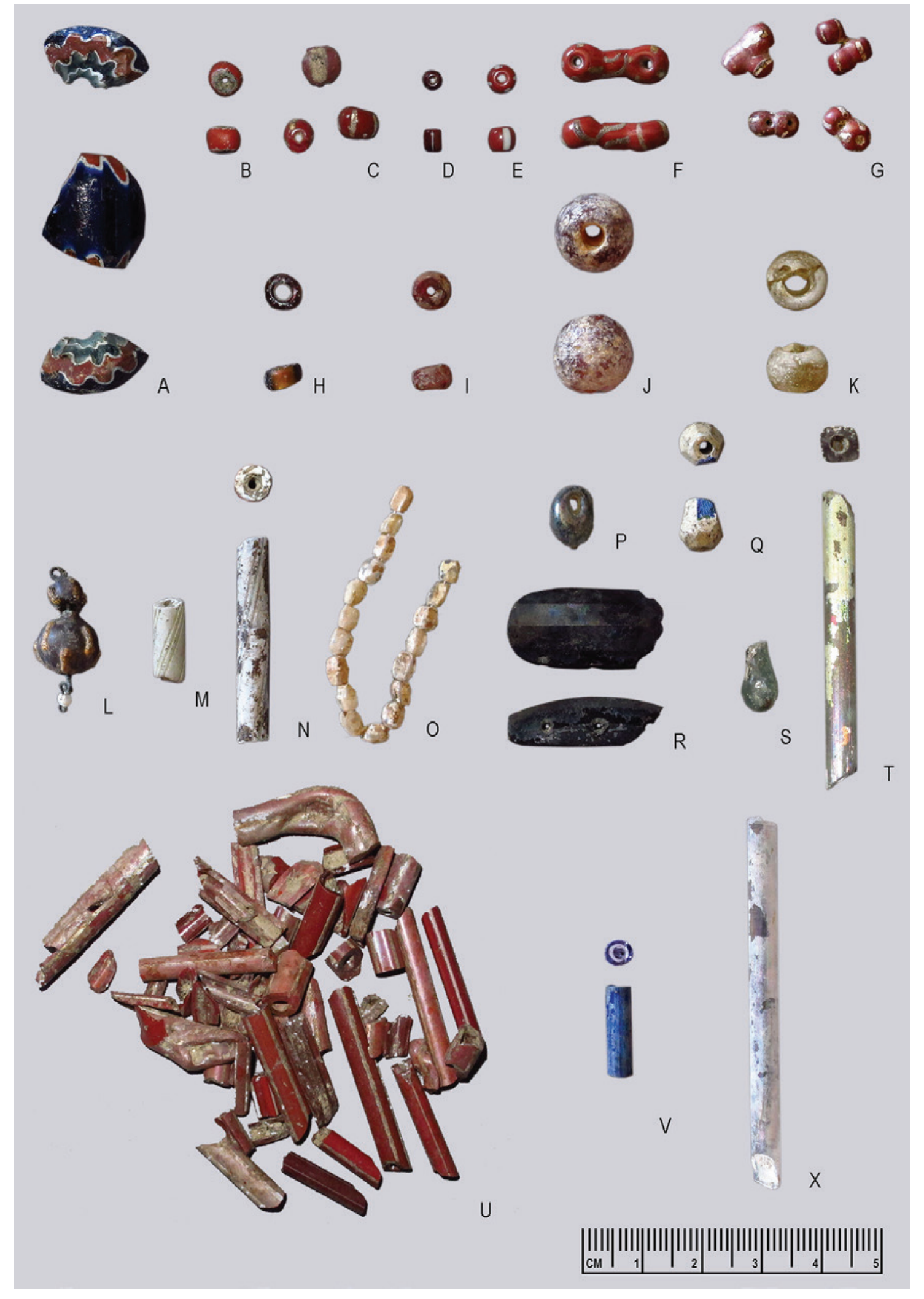

Figura 3 - Convento de Santana, Lisboa. Contas de vidro. Chevron (A. CS/Q219-6), vermelho e negro (B. CS/ Q305/C2-5), vermelho com listas brancas (C. CS/Q219-22 a 24; D. CS/Q219-25; E. CS/Q219-26; F. CS/Q21928; G. CS/Q219-29 a 32), de cor âmbar (H. CS/Oss.4-6; I. CS/F6-1655; J. CS/JardimN-1; K. CS/P-89), ocas com aplicações de vidro amarelo (L. CS/Q219-4), com decoração dourada (M. CS/Q219-35; N. CS/Q219-3), várias (O. CS/Sep.7-157 a 174; P. CS/Q219-20; Q. CS/Q307-3; R. CS/P-91; S. CS/Q219-34; T. CS/F6-1659), canas (U. CS/ Q219-33) e varas (V. CS/Q219-17; X. CS/Q182/C2-3) (fotos J. Gonçalves). 


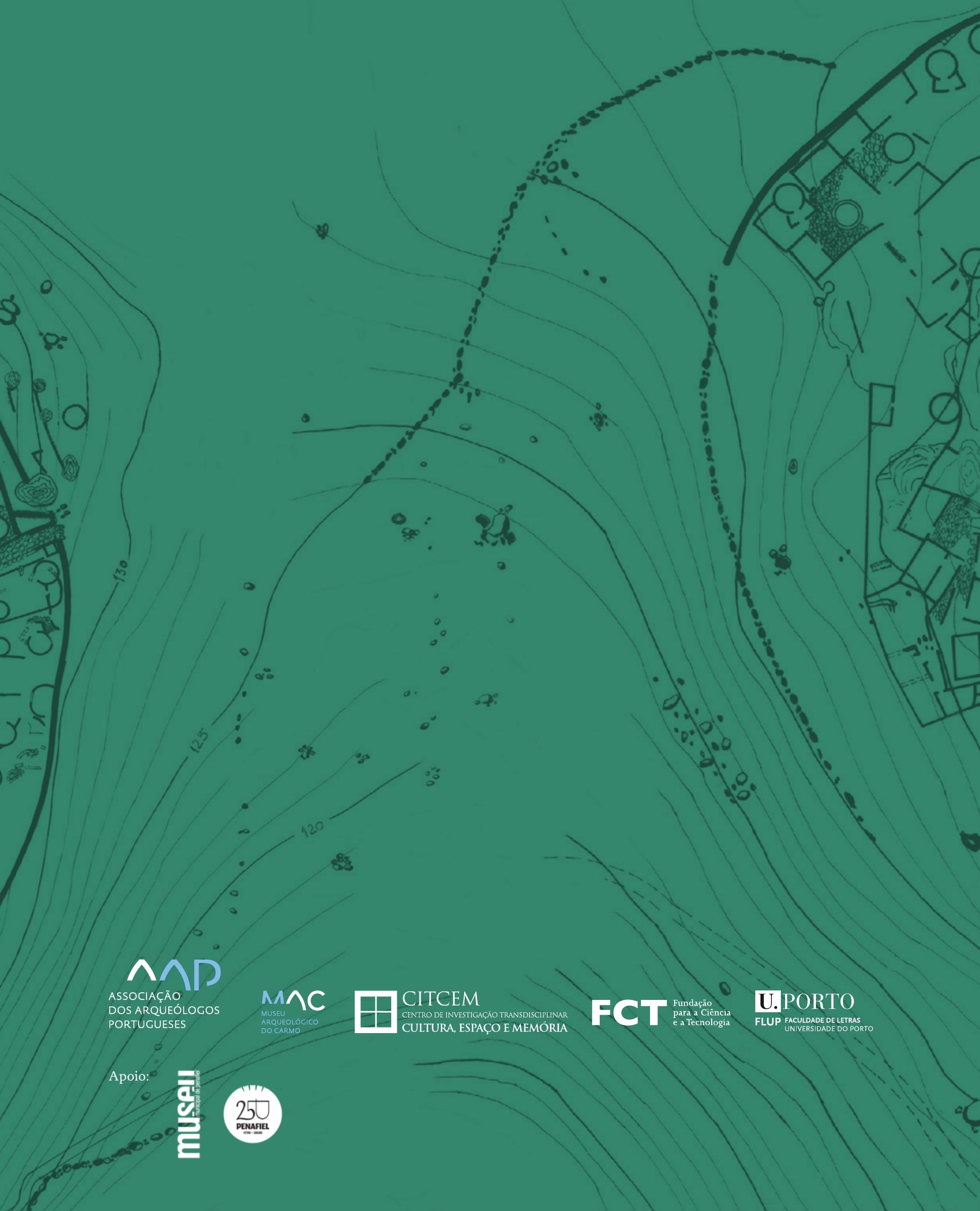

